Supporting Information

\title{
Ion Solvation Engineering: How to Manipulate the Multiplicity of the Coordination Environment of Multivalent Ions
}

\author{
Artem Baskin $^{*[a][b]}$, David Prendergast ${ }^{[a][b]}$ \\ a Joint Center for Energy Storage Research, Lawrence Berkeley National Laboratory, Berkeley, \\ CA 94720, USA \\ b The Molecular Foundry, Lawrence Berkeley National Laboratory, \\ Berkeley, CA 94720, USA
}

Correspondence to: abaskin@lbl.gov 


\section{Table of Contents}

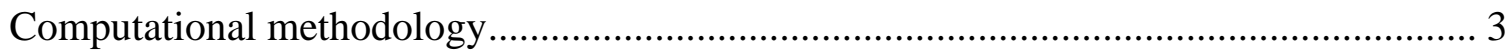

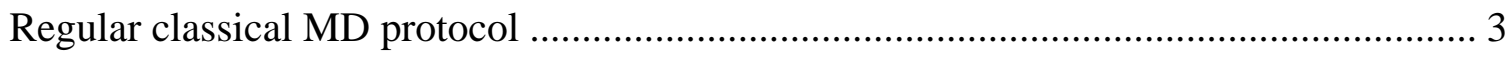

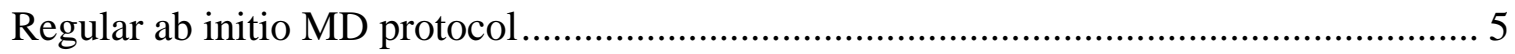

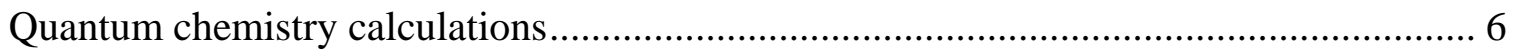

Hybrid cluster/continuum quantum mechanical calculations. Ion solvation free energy... 6

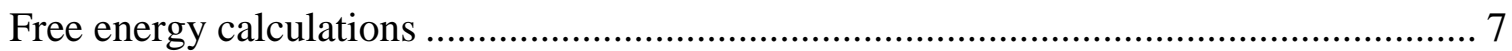

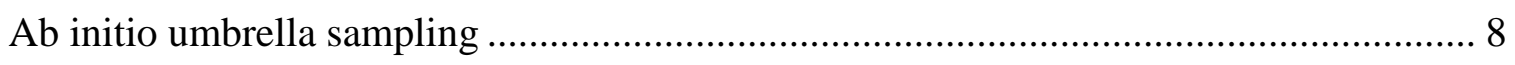

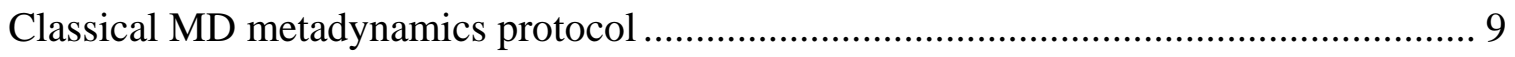

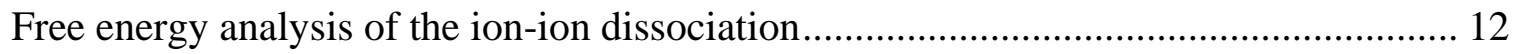

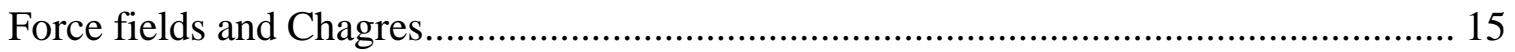

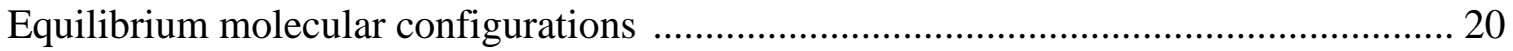

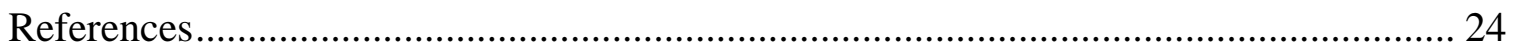




\section{Computational methodology}

We carry out regular classical and ab initio molecular dynamics simulations (MD) of cations $\left(\mathrm{Mg}^{2+}, \mathrm{Zn}^{2+}, \mathrm{Ca}^{2+}\right.$ and $\left.\mathrm{Li}^{+}\right)$in aprotic solvents and use the output equilibrated configurations as input for regular ab initio MD and quantum chemistry hybrid cluster/continuum calculations. Next, we use the metadynamics protocol and umbrella free energy sampling technique to evaluate free energy profiles along the collective variables of interest. Throughout all classical MD calculations (regular and metadynamics protocols) the Generalized Amber force field [1,2] (GAFF) was used for ions and solvent molecules. The parameters of the force field for Mg-cation and TFSI-anion and solvents (THF and G2) along with other computational details are listed below.

\section{Regular classical MD protocol}

Classical molecular dynamics (MD) simulations were conducted using the LAMMPS simulation package. [3] Long-range electrostatic interactions were treated within the particle-mesh Ewald (PME) method with a cutoff distance $1.0 \mathrm{~nm}$ with grid spacing in $k$-space of $10^{-5}$. A cut-off of $1.0 \mathrm{~nm}$ with a spline from 0.9 to $1.0 \mathrm{~nm}$ was used for Lennard-Jones interactions. The relaxation of the initial structures was performed in two steps, first using steepest descent with a convergence criterion of $10^{-4} \mathrm{kcal} \mathrm{mol}^{-1}$ for energies and $10^{-4} \mathrm{kcal} \mathrm{mol}^{-1} \AA^{-1}$ for forces. The systems were first heated to the target temperature in the canonical ensemble (NVT). To remove any "memory" effects, the systems were first melted at $500 \mathrm{~K}$ and then annealed back to the target temperature (e.g., $298 \mathrm{~K}$ ) three times (evolving the trajectory $2 \mathrm{~ns}$ for annealing each step). Then, isothermalisobaric (NPT, isotropic $P=1 \mathrm{~atm}$, at fixed target temperature) simulations were performed for 2 ns (2 fs time step) to obtain the correct density using a Nose/Hoover thermostat [4] and Nose/Hoover barostat. [5] The temperature coupling constant was $0.1 \mathrm{ps,} \mathrm{the} \mathrm{pressure} \mathrm{piston}$ constant was $2.0 \mathrm{ps}$. Afterwards, NVT simulations were performed at target temeperature for $1 \mathrm{~ns}$ ( 1 fs time step) to equilibrate. Structural properties were obtained from $5 \mathrm{~ns}$ MD simulation runs with an integration time step 1 fs in NVT ensemble with coordinates and velocities saved every 5 ps for post-trajectory analysis.

We performed simulations of an isolated $\mathrm{Mg}$-cation, the ion-pair $\mathrm{MgTFSI}^{+}$and the neutral aggregate MgTFSI2 in two solvents: tetrahydrofuran (THF) or diglyme (G2) (see Table S1 for parameters of simulations). For each case, a single ionic/neutral species was placed in a box of solvent molecules, and equilibrated as described above, and neutralizing background was used (when necessary) to properly account for electrostatic interactions. 
Table S1. Parameters of classical MD simulations.

\begin{tabular}{|c|c|c|}
\hline Simulations & \# of molecules in the box & $\begin{array}{l}\text { Equilibrated box size } \\
(\AA)\end{array}$ \\
\hline \multicolumn{3}{|l|}{ T-Dependence } \\
\hline $\mathrm{Mg}^{2+} / \mathrm{THF}, \mathrm{T}=250 \mathrm{~K}$ & $1 \mathrm{Mg}^{2+}, 511 \mathrm{THF}$ & 40.2133 \\
\hline $\mathrm{Mg}^{2+} / \mathrm{THF}, \mathrm{T}=275 \mathrm{~K}$ & $1 \mathrm{Mg}^{2+}, 511 \mathrm{THF}$ & 40.5701 \\
\hline $\mathrm{Mg}^{2+} / \mathrm{THF}, \mathrm{T}=298 \mathrm{~K}$ & $1 \mathrm{Mg}^{2+}, 511 \mathrm{THF}$ & 40.9142 \\
\hline $\mathrm{Mg}^{2+} / \mathrm{THF}, \mathrm{T}=325 \mathrm{~K}$ & $1 \mathrm{Mg}^{2+}, 511 \mathrm{THF}$ & 41.3641 \\
\hline $\mathrm{Mg}^{2+} / \mathrm{THF}, \mathrm{T}=350 \mathrm{~K}$ & $1 \mathrm{Mg}^{2+}, 511 \mathrm{THF}$ & 41.7811 \\
\hline $\mathrm{Mg}^{2+} / \mathrm{THF}, \mathrm{T}=375 \mathrm{~K}$ & $1 \mathrm{Mg}^{2+}, 511 \mathrm{THF}$ & 42.1634 \\
\hline $\mathrm{Mg}^{2+} / \mathrm{THF}, \mathrm{T}=400 \mathrm{~K}$ & $1 \mathrm{Mg}^{2+}, 511 \mathrm{THF}$ & 42.6718 \\
\hline $\mathrm{MgTFSI}^{+} / \mathrm{THF}, \mathrm{T}=250 \mathrm{~K}$ & $1 \mathrm{MgTFSI}^{+}, 510 \mathrm{THF}$ & 39.7263 \\
\hline $\mathrm{MgTFSI}^{+} / \mathrm{THF}, \mathrm{T}=298 \mathrm{~K}$ & $1 \mathrm{MgTFSI}^{+}, 510 \mathrm{THF}$ & 40.5735 \\
\hline $\mathrm{MgTFSI}^{+} / \mathrm{THF}, \mathrm{T}=400 \mathrm{~K}$ & $1 \mathrm{MgTFSI}^{+}, 510 \mathrm{THF}$ & 42.5338 \\
\hline \multicolumn{3}{|l|}{ Charge-Dependence } \\
\hline $\mathrm{Mg}^{1.2+} / \mathrm{THF}, \mathrm{T}=298 \mathrm{~K}$ & $1 \mathrm{Mg}^{1.2+}, 511 \mathrm{THF}$ & 40.9145 \\
\hline $\mathrm{Mg}^{1.6+} / \mathrm{THF}, \mathrm{T}=298 \mathrm{~K}$ & $1 \mathrm{Mg}^{1.6+}, 511 \mathrm{THF}$ & 40.9143 \\
\hline $\mathrm{Mg}^{2+} / \mathrm{THF}, \mathrm{T}=298 \mathrm{~K}$ & $1 \mathrm{Mg}^{2+}, 511 \mathrm{THF}$ & 40.9142 \\
\hline $\mathrm{Mg}^{2.2+} / \mathrm{THF}, \mathrm{T}=298 \mathrm{~K}$ & $1 \mathrm{Mg}^{2.2+}, 511 \mathrm{THF}$ & 40.9143 \\
\hline \multicolumn{3}{|c|}{ vdW-Dependence (for all $\varepsilon(L J)$ ) } \\
\hline $\mathrm{Mg}^{2+} / \mathrm{THF}, \mathrm{T}=298 \mathrm{~K}$ & $1 \mathrm{Mg}^{2+}, 511 \mathrm{THF}$ & $40.9141(5)$ \\
\hline \multicolumn{3}{|l|}{ Neutral aggregate } \\
\hline $\mathrm{MgTHSI}_{2} / \mathrm{THF}, \mathrm{T}=298 \mathrm{~K}$ & $1 \mathrm{MgTHSI}_{2}, 509 \mathrm{THF}$ & 40.5741 \\
\hline $\mathrm{MgTHSI}_{2} / \mathrm{G} 2, \mathrm{~T}=298 \mathrm{~K}$ & $1 \mathrm{MgTHSI}_{2}, 341 \mathrm{G} 2$ & 41.7153 \\
\hline \multicolumn{3}{|c|}{ Mixture of Solvents (THF and Water) } \\
\hline $\mathrm{Mg}^{2+} / \mathrm{H}_{2} \mathrm{O} / \mathrm{THF}, \mathrm{T}=298 \mathrm{~K}$ & $1 \mathrm{Mg}^{2+}, 1 \mathrm{H}_{2} \mathrm{O}, 510 \mathrm{THF}$ & 40.8600 \\
\hline $\mathrm{Mg}^{2+} / \mathrm{H}_{2} \mathrm{O} / \mathrm{THF}, \mathrm{T}=298 \mathrm{~K}$ & $1 \mathrm{Mg}^{2+}, 47 \mathrm{H}_{2} \mathrm{O}, 511 \mathrm{THF}$ & 41.1750 \\
\hline
\end{tabular}

\section{T-Dependence of a free Mg-cation solvation structure in THF}

We use regular classical MD protocol to get thermalized structures. In Table S2 we provide average coordination numbers $\overline{C N}$ of $\mathrm{Mg}$-cation (full charge +2 is used) in THF at $\mathrm{T}=298 \mathrm{~K}$ as they result from the regular MD protocol.

Table S2. Average coordination numbers of $\mathrm{Mg}$-cation in $\mathrm{THF}$ at various temperatures

\begin{tabular}{|l|l|l|l|l|l|l|l|}
\hline $\mathbf{T}, \mathbf{K}$ & 250 & 275 & 298 & 325 & 350 & 375 & 400 \\
\hline$\overline{\boldsymbol{C N}}$ & 6.0 & 6.0 & 6.0 & 5.95 & 5.75 & 5.45 & 5.4 \\
\hline
\end{tabular}




\section{The solvation structure of Mg-cation in $\mathrm{MgTFSI}^{+}$ion pair and $\mathrm{MgTFSI}_{2}$}

Since the total charge of TFSI-anion is -0.8 , we used +1.8 charge for the $\mathrm{Mg}$-ion in $\mathrm{MgTFSI}^{+}$ and +1.6 in $\mathrm{MgTFSI}_{2}$.

\section{Charge-Dependence of the solvation structure of Mg-cation in THF}

We use regular classical MD protocol to get thermalized structures for various charges of " $\mathrm{Mg}$ cation": $+1.2,+1.6,+2.0,+2.2$. In Table $\mathbf{S 3}$ we provide average coordination numbers $\overline{C N}$ of " $\mathrm{Mg}$ cation" in THF at T $=298 \mathrm{~K}$ as they result from the regular MD protocol.

Table S3. Average coordination numbers of "Mg-cation" with various charges in THF

\begin{tabular}{|l|c|c|c|c|}
\hline Charge & +1.2 & +1.6 & +2.0 & +2.2 \\
\hline$\overline{\boldsymbol{C N}}$ & 5.0 & 5.0 & 6.0 & 6.0 \\
\hline
\end{tabular}

\section{vdW-Dependence of a free Mg-cation solvation structure in THF}

We modulate the interactions of the Mg-cation with the solvent (THF) by manipulating with the vdW-parameters of Mg-oxygen (THF). We use the mix-geometric rule to get off-diagonal vdW elements: $\varepsilon_{i j}=\sqrt{\varepsilon_{i} \varepsilon_{j}}$ and $\sigma_{i j}=\sqrt{\sigma_{i} \sigma_{j}}$. Specifically, for a Mg-O pair, we use $r_{M g}=1.5852 \AA$, $\varepsilon_{M g}=0.8947 \mathrm{kcal} / \mathrm{mol}, r_{O}=3.3674 \AA$, $\varepsilon_{M g}=0.1700 \mathrm{kcal} / \mathrm{mol}$ as default values. We keep $\sigma_{M g O}=2.058332 \AA$ at its default value and vary $\varepsilon_{M g o}$ in a range $0.2,0.39,0.8,2.5,5.0,10.0$, 15.0 and $20.0 \mathrm{kcal} / \mathrm{mol}$. The charge of the $\mathrm{Mg}$-cation is fixed as $+2, \mathrm{~T}=298 \mathrm{~K}$.

\section{Regular ab initio MD protocol}

Random snapshots (i.e. set of atomic coordinates) of the equilibrated solvents with the $\mathrm{Mg}^{2+}$ ion obtained from classical MD trajectories was used as inputs for AIMD simulations. The parameters of the AIMD simulation cells are listed in Table S4. Using a sampling of $0.5 \mathrm{fs}$, AIMD simulations of ca. 10 ps within canonical NVT ensemble at $300 \mathrm{~K}$ with the Nose-Hoover thermostat [6] (with characteristic timestep of $100 \mathrm{fs}$ with the Nose-Hoover chain of length 3) and periodic boundary conditions were carried out using Quickstep module of the CP2K package [7] For non-neutral systems, the universal background compensating charge scheme and the Poisson periodic three-dimensional solver were used and the total energy was sampled at the $\Gamma$-point. The valence electrons were treated explicitly at the DFT level using the revPBE parametrization functional and a triple- $\zeta$ basis set with two additional sets of polarization functions (TZV2PX) [8] and the energy grid cutoff was set as $320 \mathrm{Ry}$. The core electrons on all atoms were treated using norm-conservative Goedecker-Teter-Hutter (GTH) pseudopotentials. [9] Long-range dispersive forces were treated with DFTD3 empirical Grimme correction. [10]. 
Table S4. Parameters of ab initio MD simulations. Experimental densities are provided in parentheses.

\begin{tabular}{|l|l|l|l|}
\hline Solvent & $\begin{array}{l}\text { \# of molecules in the } \\
\text { box }\end{array}$ & $\begin{array}{l}\text { Equilibrated box size } \\
\left(\mathrm{A}^{3}\right)\end{array}$ & Density $(\mathrm{g} / \mathrm{mL})$ \\
\hline $\mathbf{M g}^{2+} / \mathbf{A C N}^{*}$ & 56 & 17.00 & $0.785(0.786)$ \\
\hline $\mathbf{M g}^{2+} / \mathbf{T H F}^{*}$ & 25 & 15.00 & $0.890(0.883)$ \\
\hline $\mathbf{M g}^{2+} / \mathbf{G 2}^{*}$ & 14 & 15.00 & $0.940(0.937)$ \\
\hline $\mathbf{Z n}^{2+} / \mathbf{A C N}$ & 56 & 17.00 & $0.785(0.786)$ \\
\hline $\mathbf{L i}^{+} / \mathbf{A C N}$ & 56 & 17.00 & $0.785(0.786)$ \\
\hline $\mathbf{C a}^{2+} / \mathbf{T H F}$ & 25 & 15.0 & $0.887(0.883)$ \\
\hline $\mathbf{Z n}^{2+} / \mathbf{T H F}$ & 25 & 15.0 & $0.891(0.883)$ \\
\hline $\mathbf{L i}^{2+} / \mathbf{T H F}$ & 25 & 15.0 & $0.893(0.883)$ \\
\hline
\end{tabular}

*Results taken from [22]

\section{Quantum chemistry calculations}

Optimized geometries, relative energies, and molecular orbitals were calculated with the GPUbased DFT TeraChem package. [11] As suggested in the previous extensive computational studies of aprotic ionic liquids, in our calculations we used the B3LYP5-D3 functional with a number of basis sets (3-21gsp, 6-311++G**) [12] employing the third version of Grimme's empirical dispersion correction. [13] We used the L-BFGS geometry optimization method [14] with the termination criterion for the maximum energy gradient component of $4.5 \times 10^{-4}$ au. The wave function convergence threshold was set as $3.0 \times 10^{-5}$. The two-electron integral threshold was set as $1.0 \times 10^{-12}$, and the basis set linear dependency threshold was $1.0 \times 10^{-4}$. Partial charges were computed using the full natural bond orbital (NBO) and Mulliken analysis.

\section{Hybrid cluster/continuum quantum mechanical calculations.}

Polarizable continuum media (PCM) calculations with COSMO model [15] were used to evaluate the total energies and energy differences for various configurations of $\mathrm{MgTFSI}^{+}$ion-pair in THF. Solvent dielectric constant of THF was set as 7.58, and atomic radii as suggested by Bondi. [16]. The energies of the bi-coordinated, mono-coordinated and solvent separated ion-pair were calculated. The optimal configurations of $\mathrm{MgTFSI}^{+}$with $6 \mathrm{THF}$ molecules we obtained at various levels of theory. In Table S5 we show the total energies of complexes as well as the relative (to the most stable configuration) energies (Figure S1). The most stable ones are highlighted by blue.

Table S5. Absolute raw (in a.u.) and relative (in kT at $298 \mathrm{~K}$ ) energies of complexes

\begin{tabular}{|c|c|c|c|c|c|c|}
\hline Basis Set & \multicolumn{2}{|c|}{$\begin{array}{c}\mathrm{MgTFSI}^{+} / \mathrm{THF} \\
\text { (bidentate) }\end{array}$} & \multicolumn{2}{|c|}{$\begin{array}{l}\mathrm{MgTFSI}^{+} / \mathrm{THF} \\
\text { (monodentate) }\end{array}$} & \multicolumn{2}{|c|}{$\begin{array}{c}\mathrm{MgTFSI}^{+} / \mathrm{THF} \\
\text { (SSIP) }\end{array}$} \\
\hline 3-21gsp & $-3412.1412548094 \mathrm{au}$ & $0 \mathrm{kT}$ & -3412.1345626390 au & $\begin{array}{c}+7.28 \\
\mathrm{kT}\end{array}$ & $-3412.0723025467 \mathrm{au}$ & $\begin{array}{c}+75.05 \\
\mathrm{kT}\end{array}$ \\
\hline $6-311++\mathrm{G}^{* *}$ & $-3421.5329835842 \mathrm{au}$ & $\begin{array}{c}+9.06 \\
\mathrm{kT} \\
\end{array}$ & $-3421.5413087062 \mathrm{au}$ & $0 \mathrm{kT}$ & $-3421.4995007034 \mathrm{au}$ & $\begin{array}{c}+45.51 \\
\mathrm{kT} \\
\end{array}$ \\
\hline $\begin{array}{l}6-311++\mathrm{G}^{* *} \\
\mathrm{PCM} \\
\varepsilon(\mathrm{THF})=7.58\end{array}$ & $-3421.5946920988 \mathrm{au}$ & $\begin{array}{c}+17.71 \\
\mathrm{kT}\end{array}$ & $-3421.6109638478 \mathrm{au}$ & $0 \mathrm{kT}$ & $-3421.5955099042 \mathrm{au}$ & $\begin{array}{c}+16.82 \\
\mathrm{kT}\end{array}$ \\
\hline
\end{tabular}




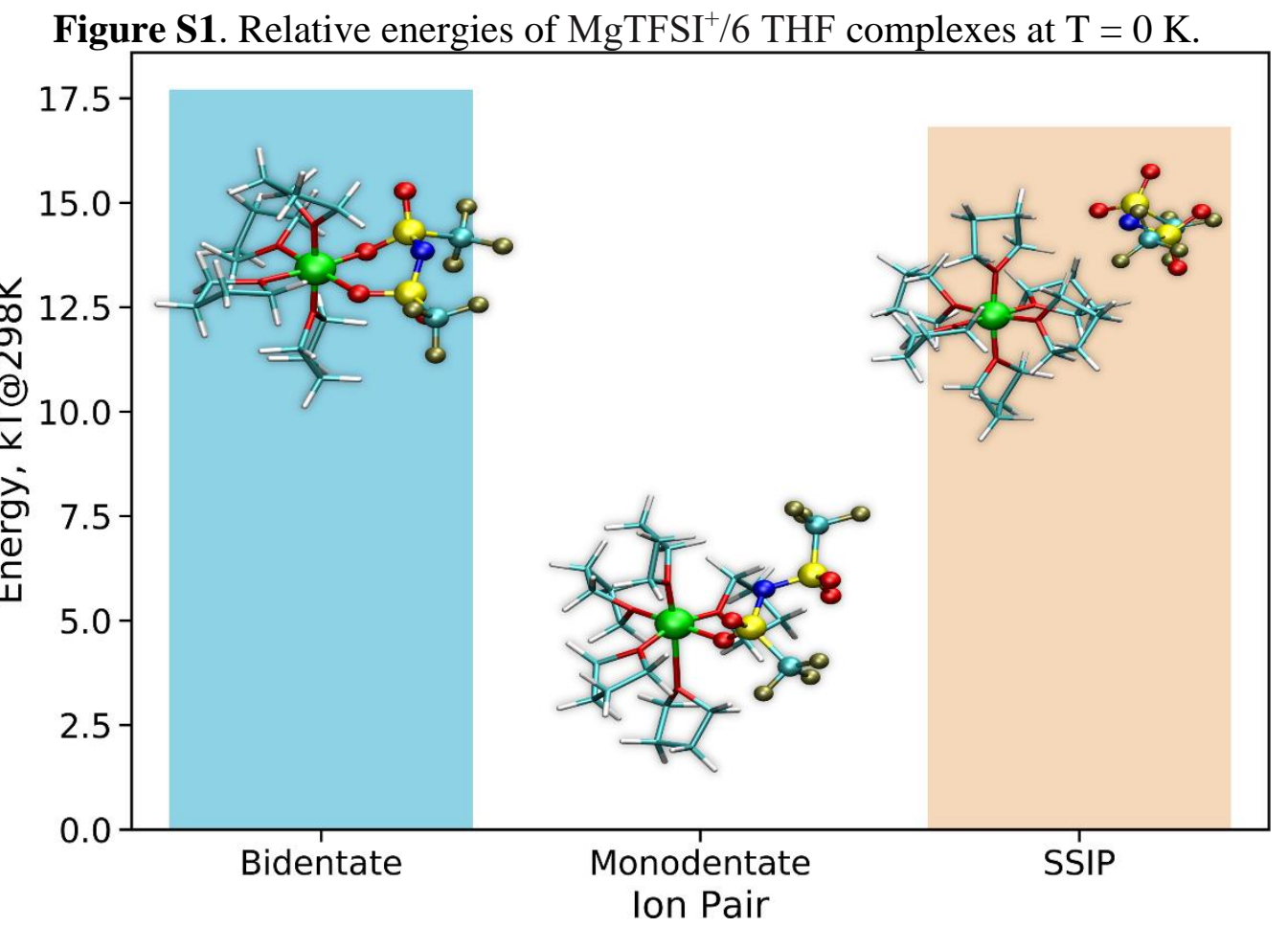

\section{Free energy calculations}

We performed ab initio and classical free energy sampling to evaluate the free energy profiles along the collective variables $(\mathrm{CV})$ : the ion-solvent or ion-anion coordination number $(\mathrm{CN})$ (see further details below) as well as the ion-anion molecule distance. Specifically, we use umbrella sampling technique [18,19] and the metadynamics [20,21] protocol to evaluate the potential of mean force along the collective variables. For a system of $\mathrm{N}$ particles in a canonical ensemble at temperature $\mathrm{T}$, the probability density associated with a generalized coordinate $\lambda$ having a value of $\lambda_{0}$ can be expressed in terms of a generalized partition function:

$$
\Omega\left(\lambda_{0}\right)=\int d q^{3 N} d p^{3 N} \delta\left(\lambda-\lambda_{0}\right) e^{-\beta H\left(q^{N}, p^{N}\right)},
$$

where $q$ and $p$ are conjugated generalized coordinates and momenta of particles and we assume that additional constraints associated with general integrals of motion are already subtracted. Accordingly, the configurational part of the partition function can be written as

$$
Z\left(\lambda_{0}\right)=\int d q^{3 N} \delta\left(\lambda-\lambda_{0}\right) e^{-\beta H\left(q^{N} ; \lambda\right)} .
$$

In a basis with no cross terms involved, we rewrite the probability density as:

$$
\Omega(\lambda)=\int d q^{3 N-1} d p^{3 N-1} d P_{\lambda} e^{-\beta H\left(q^{N}, p^{N}, P_{\lambda}\right)},
$$

where we integrate out all degrees of freedom and conjugated momenta except the coordinate of interest, $\lambda$. The PMF is then defined as $W(\lambda)=-k T \ln \Omega(\lambda)+$ const.

The integration constant is chosen so $\min \{W(\lambda)\}=W\left(\lambda_{\text {min }}\right)=0$, where $\lambda_{\text {min }}$ - is the value of $\mathrm{CV}$ at which $W(\lambda)$ reaches its global minima.

For a given reaction coordinate $\lambda$, the PMF $W(\lambda)$ can also be expressed as follows:

$$
W(\lambda)=k T \ln \left[\int e^{+\beta H\left(q^{N-1} ; \lambda\right)} \operatorname{Pr}\left(q^{N-1} ; \lambda\right) d q^{N-1}\right],
$$

where $H\left(q^{N} ; \lambda\right)$ is the energy of a conditional configuration $\left(q^{N-1} ; \lambda\right)$ and 


$$
\operatorname{Pr}\left(q^{N-1} ; \lambda\right)=\frac{e^{-\beta H\left(q^{N-1} ; \lambda\right)}}{\int e^{-\beta H\left(q^{N-1} ; \lambda\right)} d q^{N-1}}
$$

is the probability of that conditional configuration directly related to the partition function $Z(\lambda)$. The sampling effectively integrates out all the other degrees of freedom, except $\lambda$, and in this light it can be viewed as integration over the basin, because the associated values of the PMF at various values of the reaction coordinate $\lambda$ account for the Boltzmann statistics of states $\left(q^{N-1} ; \lambda\right)$.

\section{Definition of the coordination number}

We use the following functional form of the coordination number $\mathrm{CN}$ :

$C N=\sum_{i=1}^{N} \frac{1-\left(\frac{r_{i}}{r_{0}}\right)^{p}}{1-\left(\frac{r_{i}}{r_{o}}\right)^{q}}$, where $\mathrm{p}=6, \mathrm{q}=12, \mathrm{r}_{\mathrm{i}}-$ is the distance between the ion and the particular atom of the i-th solvent molecule (e.g., oxygen atom in THF), $r_{o}$ - the cut-off radius that separates atoms that belong to the solvation sphere from those that do not, and i runs over the range that includes all possible coordinating atoms (e.g., all oxygen atoms in the simulation box of $\mathrm{Mg}^{2+}$ in THF). Cut-off radii we defined using the following procedure. For a regular classical or AIMD protocol, we define $\mathrm{CN}$ of the ion by calculating the integrated $\mathrm{g}(\mathrm{r})$. We then vary the cut-off radius ro to achieve the same CN for unbiased classical or AIMD (no Gaussians added, force constant $\varkappa=0$ ) as from the regular (AI)MD protocol.

\section{Ab initio umbrella sampling}

For each ion, we defined the sampling windows of $\mathrm{CN}$ and apply harmonic umbrella potentials of the form $U_{i}(C N)=\varkappa_{i}\left(C N-C N_{i}\right)^{2}$, where $\mathrm{i}$ - is the $\mathrm{i}$-th window, $\varkappa_{i}$ - the force constant for the i-th window and $C N_{i}$-is the target coordination number for the i-th window. For each umbrella window, a trajectory of $20 \mathrm{ps}$ was collected after $2 \mathrm{ps}$ of equilibration. Overall simulation time of these five systems is $2.046 \mathrm{~ns}$. The weighted histogram analysis method (WHAM) [22] was used to construct the free energy profiles from these histograms. The parameters $\left(\mathrm{r}_{0}, \varkappa_{i}\right)$ for each simulation are summarized in Table $\mathbf{S 6 .}$

Table S6. Parameters of ab initio umbrella samplings.

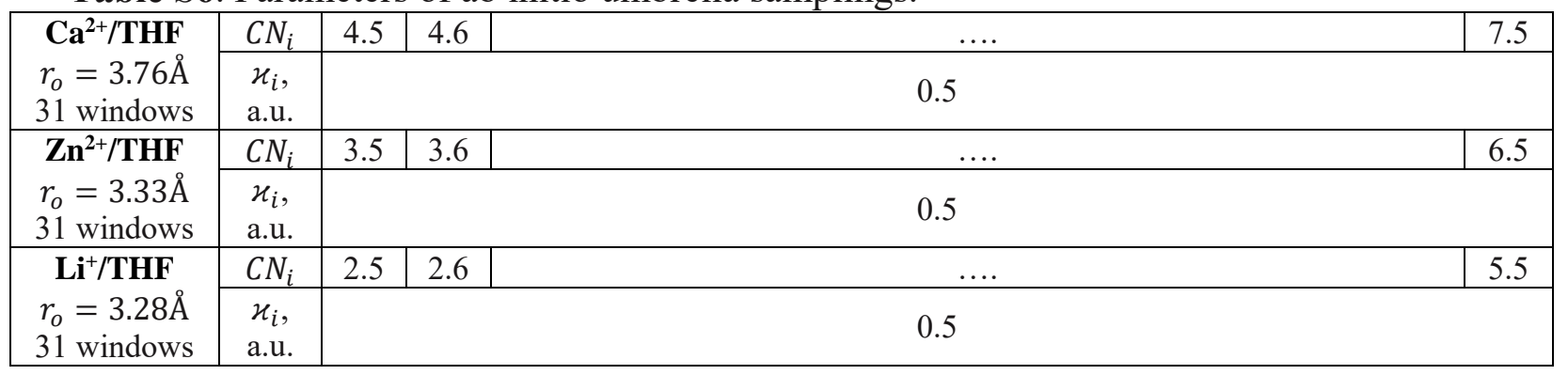

Accuracy of the free energy calculations from umbrella sampling critically depends on the density of the sampling windows and the overlapping of adjacent probability distributions. Here we used parameters that were proven [22] to provide the efficient overlapping and thus the convergence of WHAM algorithm. 
Figure S2. Ab Initio umbrella sampling analysis of solvation structures of $\mathrm{Li}^{+}, \mathrm{Mg}^{2+}, \mathrm{Ca}^{2+}$ and $\mathrm{Zn}^{2+}$ in acetonitrile $(\mathrm{ACN})$, tetrahydrofuran (THF) an diglyme $(\mathrm{G} 2)$. The most stable solvation structures of cations are shown.
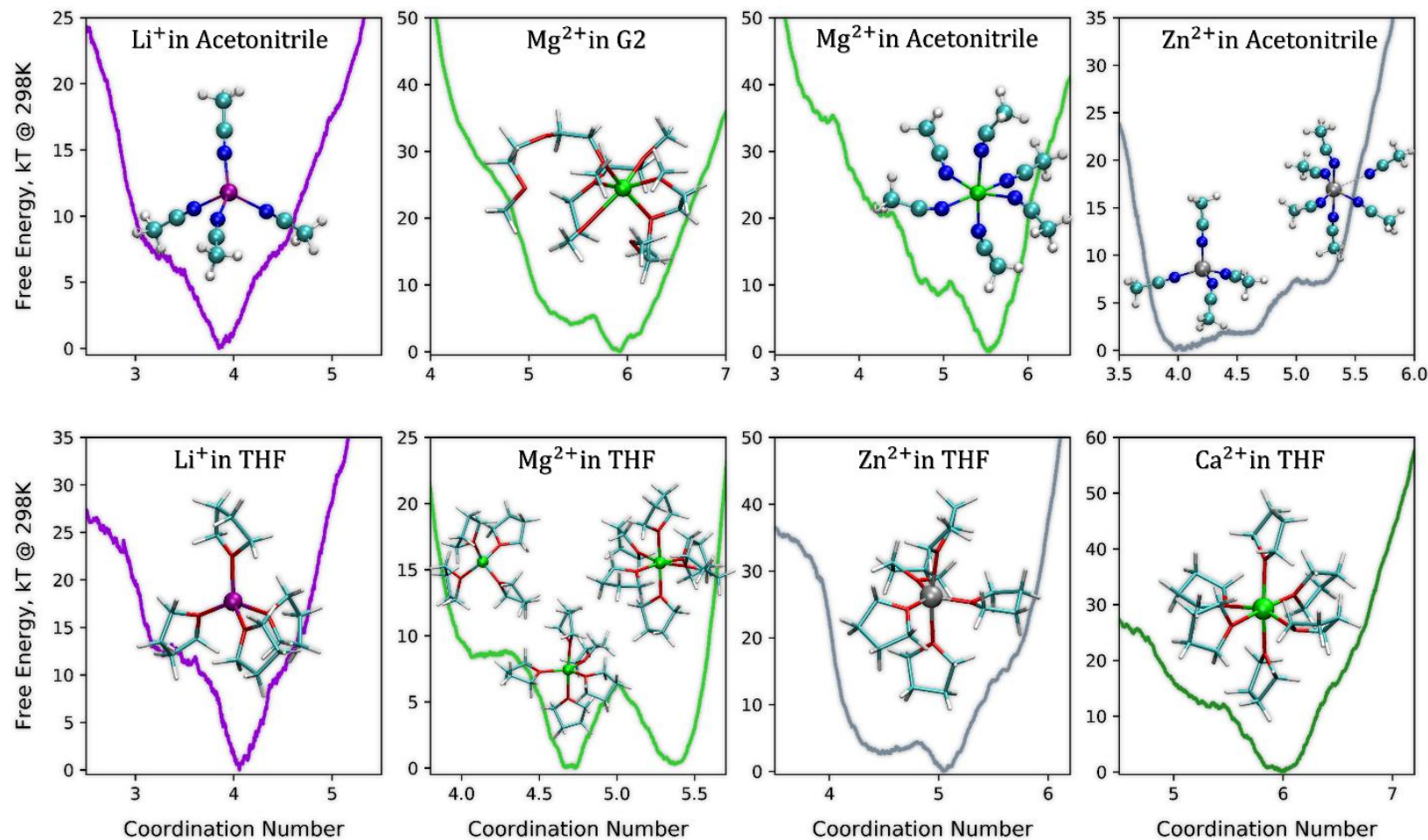

\section{Classical MD metadynamics protocol}

Equilibrated boxes of solvents with ions (see regular classical MD protocol section) were used as initial configuration for free energy sampling with the metadynamics protocol. We use two sets of collective variables to explore the free energy landscape of the free $\mathrm{Mg}$-cation solvation in THF and $\mathrm{G} 2$ solvents. One collective variable is the ion coordination number, $\mathrm{CN}$, (the same definition as for the umbrella sampling) and the distance between the cation and the solvent molecules (i.e., the oxygen). For $\mathrm{MgTFSI}^{+}$ion-pair and $\mathrm{MgTFSI}_{2}$ we used $\mathrm{CN}$ of $\mathrm{Mg}$-cation with respect to oxygens of solvent and oxygens of anion (4 oxygens in each TFSI-anion). We also used the distance between $\mathrm{Mg}$-cation and the center of masses of sulfones ( $\mathrm{SO}_{2}$-groups) as a collective variable to probe the free energy landscape of the dissociation of $\mathrm{MgTFSI}_{2}$.

In Tables S7-S9 we summarize the parameters of the metadynamics free energy sampling for various simulations: height of the Gaussian hills $(\mathrm{H}, \mathrm{kcal} / \mathrm{mol})$, frequency of hill creation (freq, steps), and width of hills (W, either Angströms for CV - distance or unitless for CV - coordination number) along with the ranges for the collective variables, the cut-off radius ( $\mathrm{r}_{\mathrm{o}}, \AA$ ) for $\mathrm{CN}$ and the overall simulation times (Time, nanoseconds) for each system. 
Table S7. Parameters of classical MD metadynamics free energy sampling.

\begin{tabular}{|c|c|c|c|c|}
\hline & $\begin{array}{l}\mathbf{M g}^{2+} / \mathrm{THF} \\
\text { T-Dependence } \\
\mathbf{2 5 0}-\mathbf{4 0 0} \mathbf{K} \\
\mathrm{CN}[4 ; 6.5] \\
\mathrm{r}_{\mathrm{o}}=3.07 \AA \\
\end{array}$ & $\begin{array}{l}\text { MgTFSI }^{+} / \mathrm{THF} \\
\text { T-Dependence } \\
\text { 250, 298, 400 K } \\
\mathrm{CN}[2.9 ; 6.5] \\
\mathrm{r}_{\mathrm{o}}=3.07 \AA \\
\end{array}$ & $\begin{array}{l}\mathrm{Mg}^{\mathrm{Q}+} / \mathrm{THF} \\
\text { Charge-Dependence } \\
\mathrm{Q}(\mathrm{Mg})=+1.2,+1.6,+2.0,+2.2 \\
\mathrm{CN}[4.0 ; 6.2] \\
\mathrm{r}_{\mathrm{o}}=3.07 \AA . \mathrm{A}=298 \mathrm{~K}\end{array}$ & $\begin{array}{l}\mathrm{Mg}^{2+} / \mathrm{THF} \\
\text { vdW-Dependence } \\
\varepsilon=0.2 \ldots 20.0 \mathrm{~kJ} / \mathrm{mol} \\
\mathrm{CN}[4.0 ; 7.5] \\
\mathrm{r}_{\mathrm{o}}=3.07 \AA, \mathrm{T}=298 \mathrm{~K}\end{array}$ \\
\hline $\mathrm{H}$ & 0.01 & 0.01 & 0.01 & 0.01 \\
\hline $\mathrm{W}$ & 0.01 & 0.01 & 0.01 & 0.01 \\
\hline freq & 1000 & 1000 & 1000 & 1000 \\
\hline Time & 800 & 1200 & 1000 & 1000 \\
\hline
\end{tabular}

Table S8. Parameters of classical MD metadynamics free energy sampling.

\begin{tabular}{|c|c|c|c|c|}
\hline & $\begin{array}{l}\text { MgTFSI } 2 / \text { THF } \\
\text { Coordination } \\
\mathrm{T}=298 \mathrm{~K} \\
\mathrm{CN} 1[1.8 ; 6.2], \mathrm{CN} 2[0.0 ; 4.5] \\
\mathrm{r}_{\mathrm{o} 1}=3.07 \AA \mathrm{r}_{\mathrm{o} 2}=3.07 \AA\end{array}$ & $\begin{array}{l}\text { MgTFSI }_{2} / \mathbf{T H F} \\
\text { Dissociation } \\
\mathrm{T}=298 \mathrm{~K} \\
\text { d1 }[1.0 ; 15] \AA \\
\text { d2 }[1.0 ; 15] \AA \\
\end{array}$ & $\begin{array}{l}\text { MgTFSI }_{2} / \mathbf{G 2} \\
\text { Coordination } \\
\mathrm{T}=298 \mathrm{~K} \\
\mathrm{CN} 1[1.8 ; 6.2], \mathrm{CN} 2[0.0 ; 4.2] \\
\mathrm{r}_{\mathrm{o} 1}=2.75 \AA \mathrm{r}_{\mathrm{o} 2}=2.75 \AA\end{array}$ & $\begin{array}{l}\text { MgTFSI }_{2} / \mathbf{G 2} \\
\text { Dissociation } \\
\mathrm{T}=298 \mathrm{~K} \\
\mathrm{~d} 1[1.0 ; 15] \AA \\
\mathrm{d} 2[1.0 ; 15] \AA \\
\end{array}$ \\
\hline $\mathrm{H}$ & 0.02 & 0.02 & 0.01 & 0.02 \\
\hline $\mathrm{W}$ & 0.02 & 0.05 & 0.02 & 0.05 \\
\hline freq & 200 & 200 & 200 & 200 \\
\hline Time & 1400 & 1200 & 1200 & 1200 \\
\hline
\end{tabular}

Table S9. Parameters of classical MD metadynamics free energy sampling.

\begin{tabular}{|l|l|l|}
\hline & $\begin{array}{l}\mathbf{M g}^{2+} / \mathbf{T H F}+\mathbf{1} \mathbf{H}_{\mathbf{2}} \mathbf{O} \\
\text { Dissociation } \\
\mathrm{T}=298 \mathrm{~K} \\
\mathrm{~d}[1.5 ; 10] \AA\end{array}$ & $\begin{array}{l}\mathbf{M g}^{\mathbf{2}+} / \mathbf{T H F}+\mathbf{1} \mathbf{M} \mathbf{H}_{\mathbf{2}} \mathbf{O} \\
\mathbf{C o o r d i n a t i o n} \\
\mathrm{T}=298 \mathrm{~K} \\
\mathrm{CN} 1[0 ; 6.2], \mathrm{CN} 2[0.0 ; 7.0] \\
\mathrm{r}_{\mathrm{o} 1}=3.07 \AA, \mathrm{r}_{\mathrm{o} 2}=2.90 \AA\end{array}$ \\
\hline $\mathrm{H}$ & 0.01 & 0.02 \\
\hline $\mathrm{W}$ & 0.02 & 0.1 \\
\hline freq & 1000 & 200 \\
\hline Time & 1000 & 1200 \\
\hline
\end{tabular}

As suggested [21], the convergence of the free energy sampling by the metadynamics protocol is reached when one reaches the diffusive motion along the CV. Here we used parameters of sampling ( $\mathrm{H}, \mathrm{W}$, freq and time) that guarantee [22] the convergence (diffusive regime) at the end of sampling time.

\section{T-Dependence of a free Mg-cation solvation structure in THF}

Upon achieving the convergence of the metadynamics protocol, the free energies for each temperature as functions of $\mathrm{Mg}$-cation coordination number $\Delta G(C N)$ (vs. oxygens of THF) are averaged over last $10 \mathrm{~ns}$ (1000 random free energy profiles are used): $\overline{\Delta G(C N)}=\frac{1}{N} \sum_{i=1}^{N} \Delta G_{i}(C N)$, where $\Delta G_{i}(C N)$ - is the $\mathrm{i}^{\text {th }}$ free energy profile converged by the time i. In Figure 1 (main text) we show only $\overline{\Delta G(C N)}$. An example of the averaged free energy profile (at $\mathrm{T}=298 \mathrm{~K}$ ) along with the 1000 other profiles (over last $10 \mathrm{~ns}$ ) is shown in Figure S3. 
Figure S3. Free energy profile for the solvation structure of $\mathrm{Mg}^{2+} / \mathrm{THF}$ at $\mathrm{T}=298 \mathrm{~K}$, averaged (shaded area) over last random 1000 profiles (last $10 \mathrm{~ns}$ of sampling). Stable configurations are marked with $\mathrm{C}_{1}$ and $\mathrm{C}_{2}$, respectively. Free energy difference $\Delta G_{c 1 c 2}$ between free energies of stable configurations is indicated along with the free energy barriers $\Delta G_{c 1}^{+}$and $\Delta G_{c 2}^{+}$.

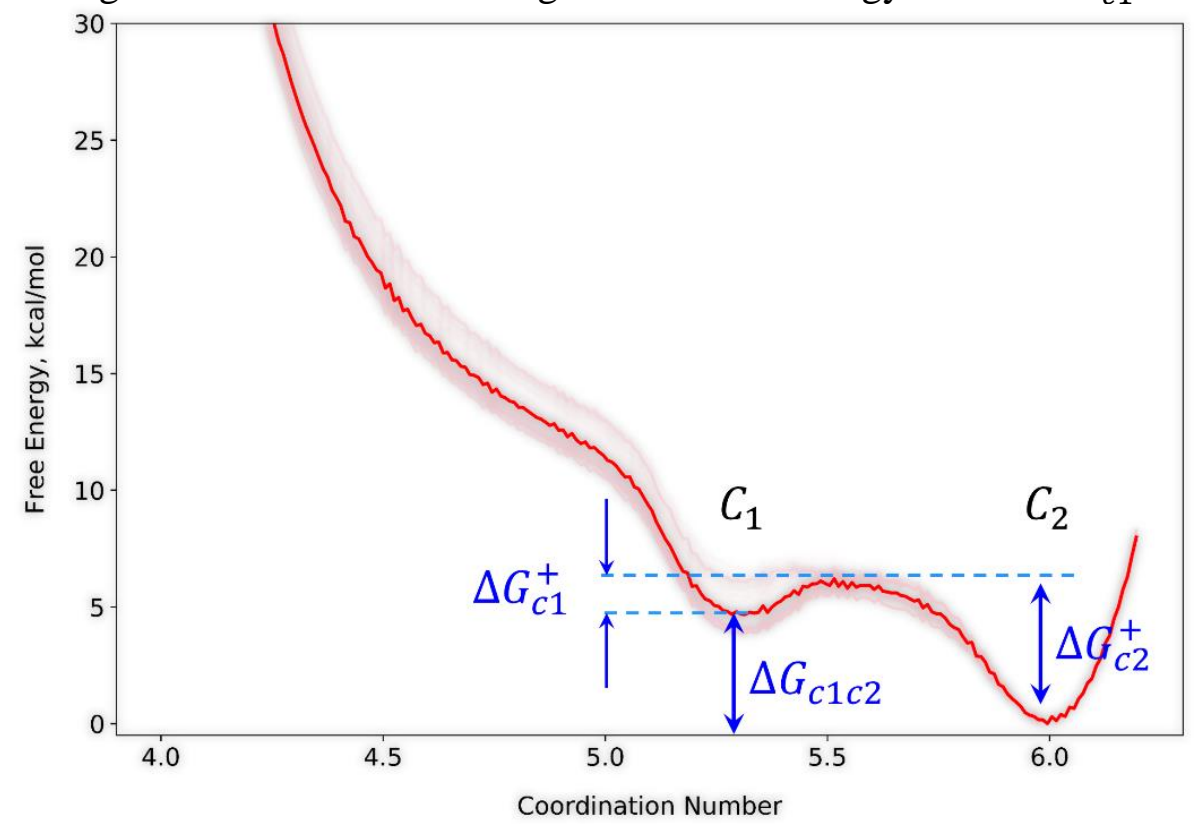

T-dependence of kinetic barriers $\Delta G_{c 1}^{+}$and $\Delta G_{c 2}^{+}$is shown in Figure S4.

Figure S4. T-dependence of kinetic barriers $\Delta G_{c 1}^{+}$and $\Delta G_{c 2}^{+}$(see Figure S3)

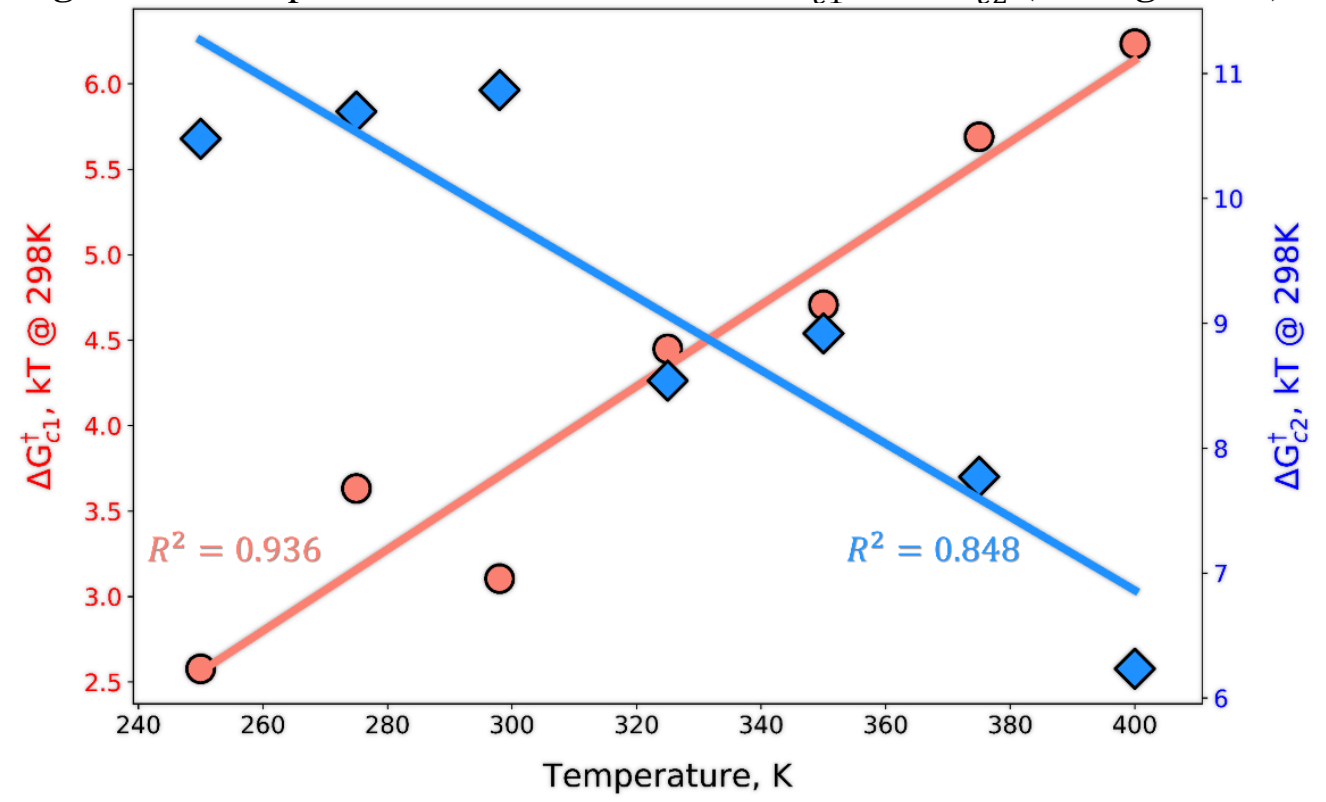

\section{Charge-Dependence of a free Mg-cation solvation structure in THF}

Upon achieving the convergence of the metadynamics protocol, the free energies for each charge as functions of $\mathrm{Mg}$-cation coordination number $\Delta G(C N)$ (vs. oxygens of THF) are averaged 
over last $10 \mathrm{~ns}$ (1000 random free energy profiles are used): $\overline{\Delta G(C N)}=\frac{1}{N} \sum_{i=1}^{N} \Delta G_{i}(C N)$, where $\Delta G_{i}(C N)-$ is the $\mathrm{i}^{\text {th }}$ free energy profile converged by the time i. In Figure 2 (main text) we show only $\overline{\Delta G(C N)}$.

\section{vdW-Dependence of a free Mg-cation solvation structure in THF}

The dependence of stable coordination configurations of the Mg-cation on the parameters of off-diagonal vdW energy parameters $\varepsilon_{M g O}(L J)$ is shown in Figure $\mathbf{S 5}$.

Figure S5. vdW-dependence of stable coordination configurations. $C N_{1}, C N_{2}$ and $C N_{3}$ stand for lower, higher and new higher stable coordination configurations. Filled circles signify the coordination numbers that correspond to the most stable solvation configuration for each $\varepsilon_{M g O}(L J)$. The default value $\varepsilon_{M g O}(L J)=0.39 \mathrm{kcal} / \mathrm{mol}$ is shown by a dotted line.

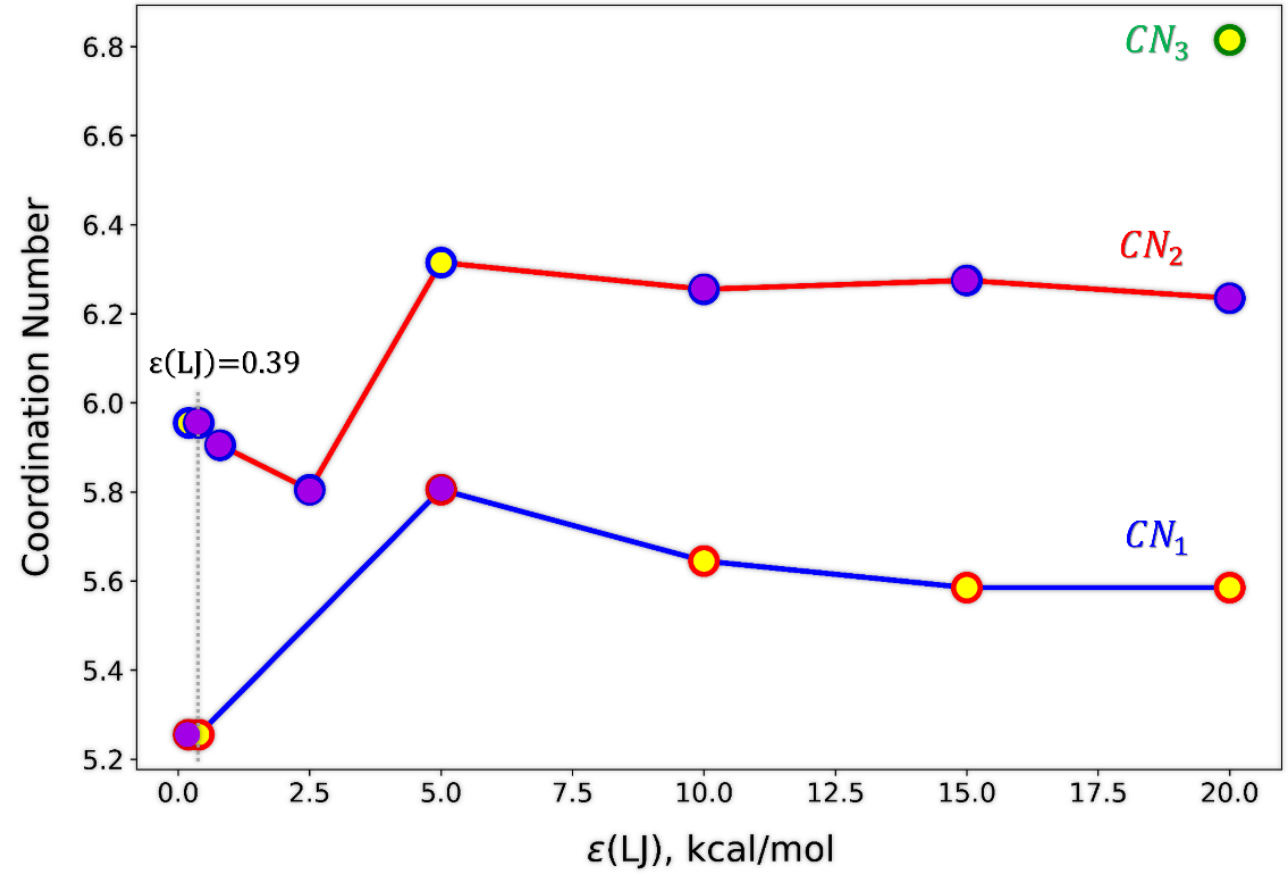

Free energy analysis of ion-ion dissociation in low permittivity solvents (THF, G2)

When analyzing the dissociation of ionic species in low permittivity solvents at finite salt concentration we rely on the "single particle" free energy analysis when the dissociation of a particular pair of ions is probed with the free energy sampling whereas other ions and solvent play a role of a "mean-filed" providing Debye ionic and dielectric screening, respectively. As long as the screening "mean-fields" are correct, then by using the ion-ion distance as a collective variable we should see a stable bound and a stable dissociated state as depicted in Figure S6. Here we show a schematic of a free energy profile along this collective variable, where a kinetic barrier separates the stable states. In this specific instance, the dissociated state is less stable than a bound one. The difference of free energies $\Delta G_{d i s}$ at a distance compared to the average ion-ion distance $a_{o}$ for this specific salt concentration $n$ can be then used to evaluate a relative population of ion-pairs versus free solvated ions $\frac{n_{\text {dis }}}{n_{\text {ion-pair }}}=e^{-\frac{\Delta G_{\text {dis }}}{k T}}$. 
Figure S6. A schematic free energy profile of the ion-ion dissociation with the relative ion-ion distance as a collective variable. A kinetic barrier separates stable states.

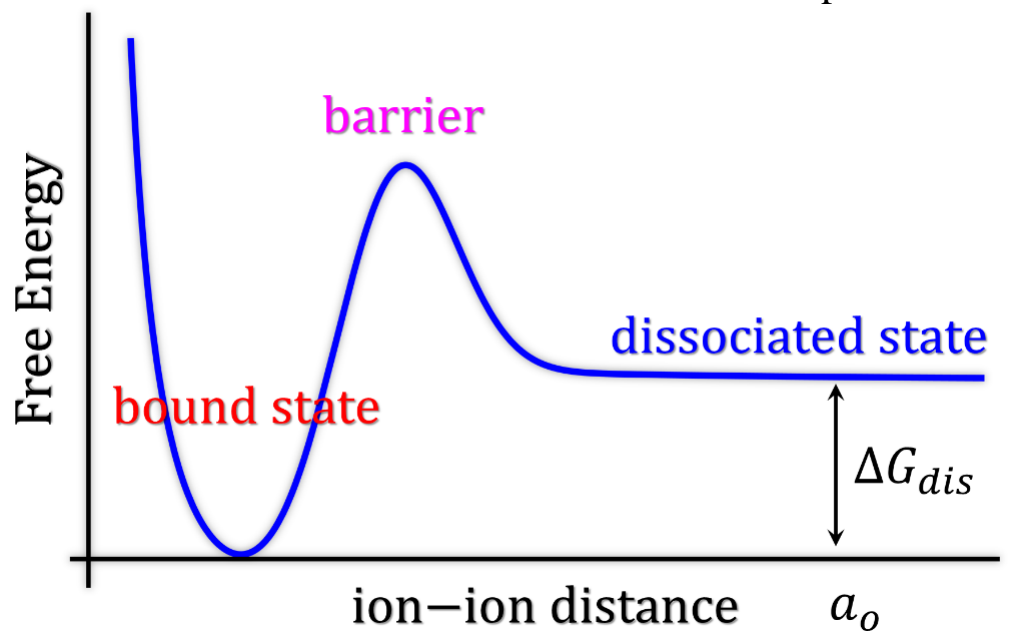

Since we use the metadynamics protocol for probing the free energy along the ion-ion distance, we do not need to account for an additional $2 k T \ln (r)$ term [23] since the reference point (zero free energy) is defined on the fly by the protocol.

For a salt of a finite concentration we define two screening length scales: the Bjerrum

$l_{B}[\AA]=\frac{576.2}{\varepsilon}$ and the Debye $l_{D}[\AA]=0.341 \sqrt{\frac{\varepsilon}{n[M]}}$, where $\varepsilon-$ is the effective dielectric constant of the electrolyte, $n[M]$ - the nominal salt concentration. The most efficient mechanism of screening is characterized by the shortest screening length scale. In Figure S7 we show $l_{s c r}=$ $\min \left(l_{B}, l_{D}\right)$ as a function of dielectric constant $\varepsilon$ for a particular salt concentration $n[M]$.

Figure S7. The screening length scales, $l_{B}$ and $l_{D}$ along the shortest $l_{s c r}=\min \left(l_{B}, l_{D}\right)$ (red dashed line) as functions of dielectric constant $\varepsilon$.

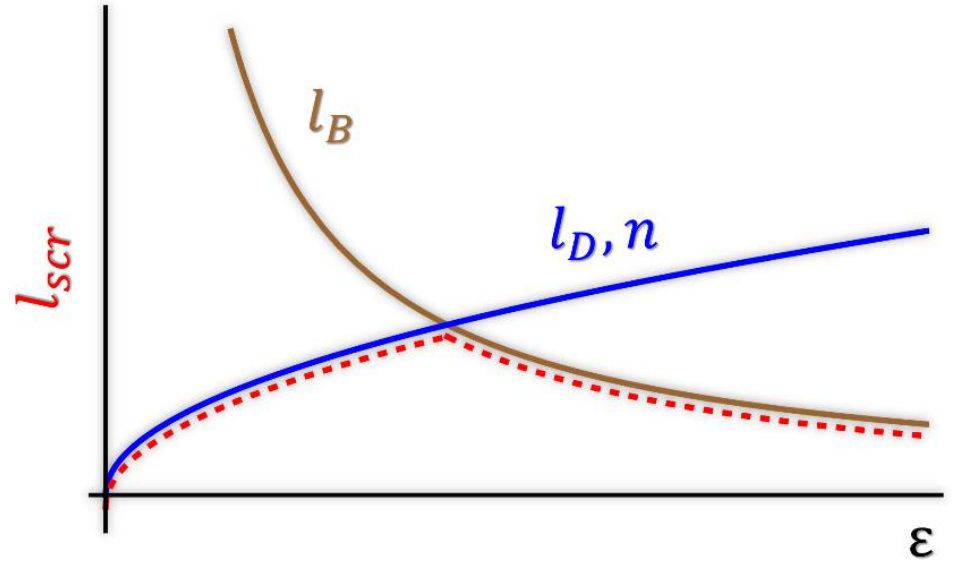


The 2D free energy analysis of dissociation of $\mathrm{MgTFSI}_{2}$ in THF and $\mathrm{G} 2$ at infinite dilution with mutual distances between Mg-cation and TFSI-anions as CV (Figure S8) show that neither the full dissociation Mg-cation - 2TFSI-anions (black lines a, d) nor the partial one $\mathrm{MgTFSI}^{+}-$ TFSI $^{-}$(blue and red lines b, c and e, f) is stable due to the lack of the Debye ionic screening. Therefore, $\Delta G_{d i s}$ at the cation-anion distance of $a_{o}=15 \AA$ cannot be used to evaluate the dissociation constant and the relative population of free ions vs. ion-pairs. The analysis also reveals multiple local free energy minima at shorter ion-ion distances that correspond to mono- and (di)bidentate $\mathrm{MgTFSI}^{+}$ion-pairs with either TFSI-anions or SSIP.

Figure S8. 2D free energy analysis of the $\operatorname{Mg}(\mathrm{TFSI})_{2}$ dissociation in THF (top left panel) and diglyme (top right panel). Distances between $\mathrm{Mg}$-cation and centers of masses of $\mathrm{SO} 2$ groups of both TFSI-anions are used as collective variable for the 2D free sampling. 1D slices along paths (indicated by black, blue and red dotted lines) are shown in panels a, b, c for THF, and d, e, f for diglyme, respectively. All free energies are in $\mathrm{kT}$ units at $\mathrm{T}=298 \mathrm{~K}$.
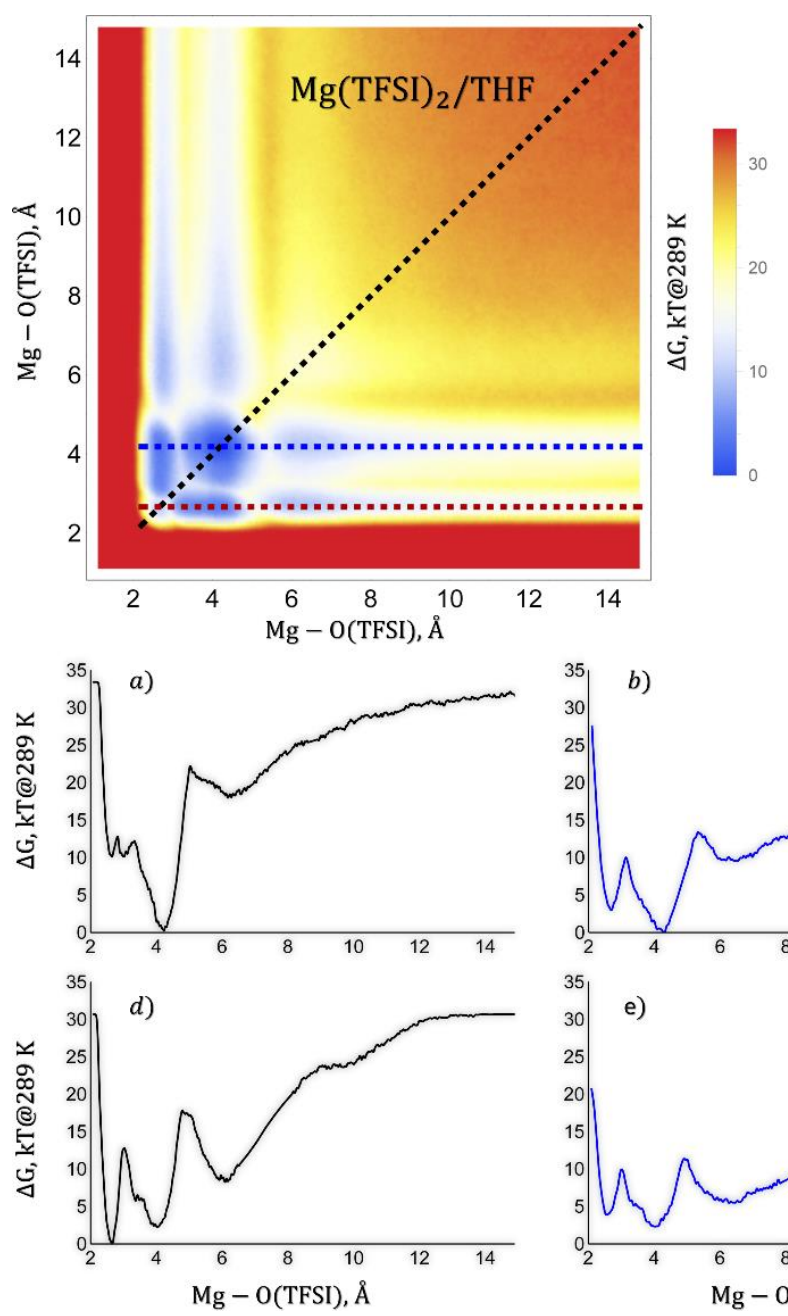
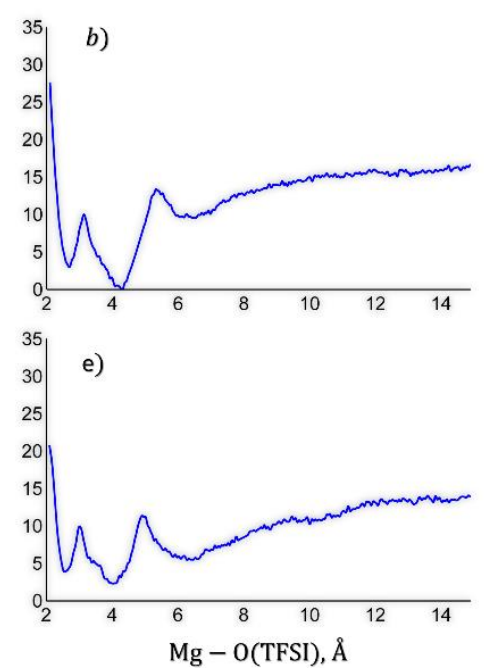
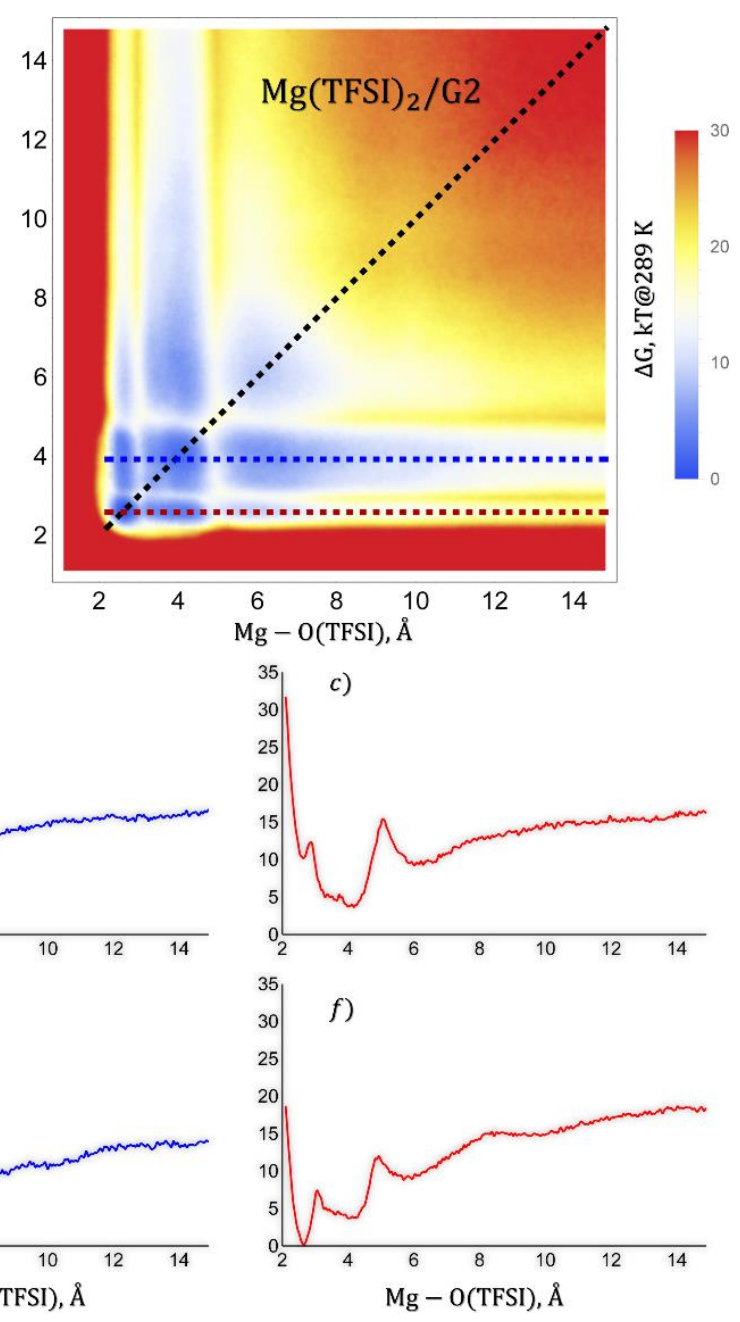


\section{Force Fields and Charges}

Standard Charges for Elements in the simulations:

TFSI-anion

$\mathrm{N} \quad-0.58800$

S $\quad 0.91100$

O $\quad-0.46100$

C $\quad 0.31900$

F -0.13800

\section{THF}

C1 0.12740

C2 -0.10640

$\begin{array}{ll}\mathrm{O} & -0.42760\end{array}$

H1 0.05170

$\mathrm{H} 2 \quad 0.04470$

G2

O1 -0.42560

O2 -0.42460

C1 0.11870

$\mathrm{C} 2 \quad 0.12440$

C3 0.13040

H1 0.03370

$\begin{array}{ll}\mathrm{H} 2 & 0.03970\end{array}$

H3 0.04170

\section{Force Fields}

Mg-cation/THF

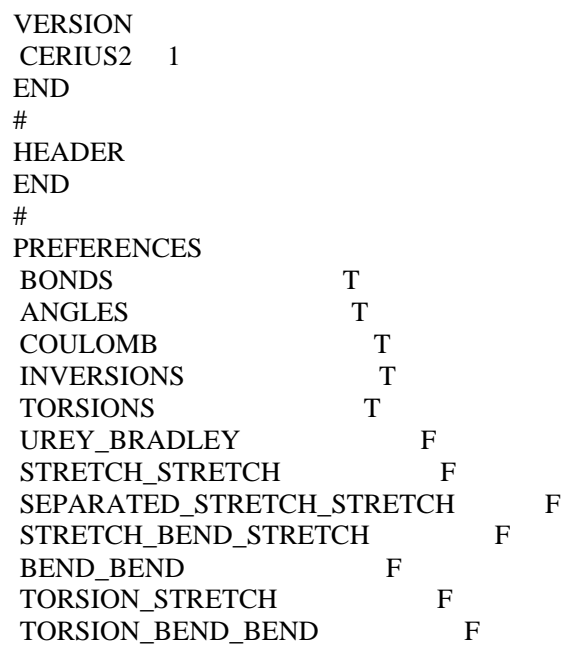




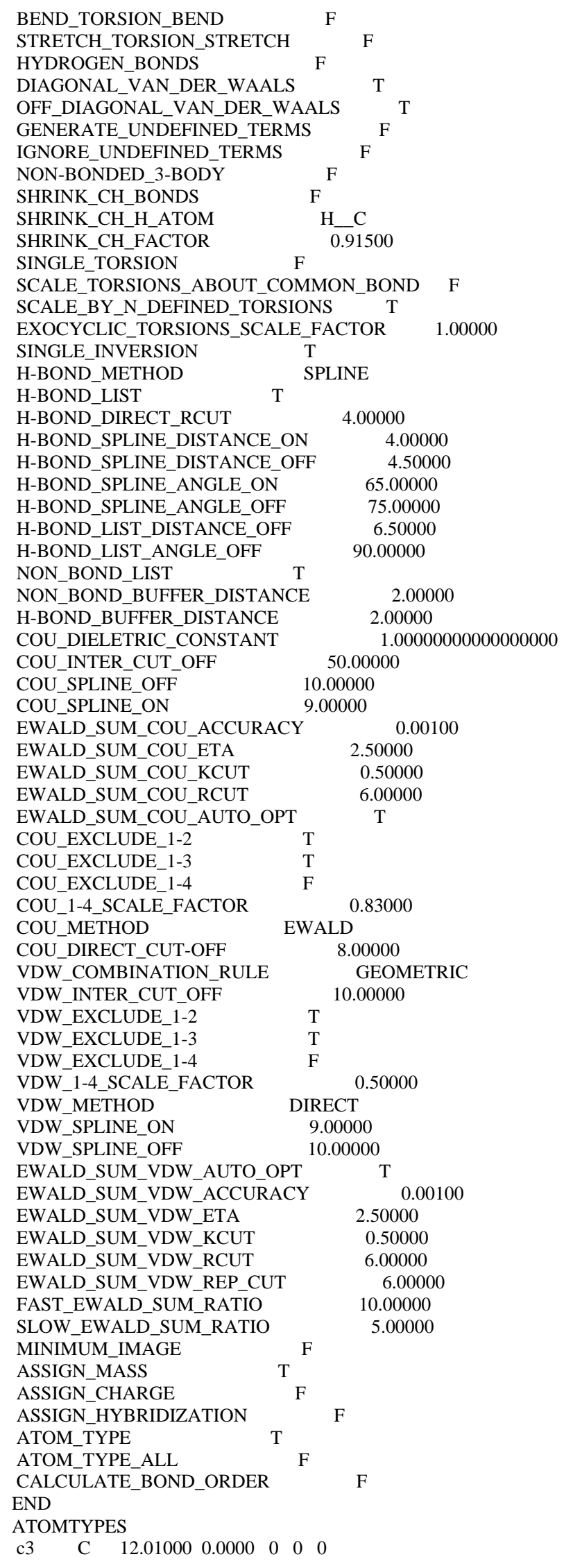




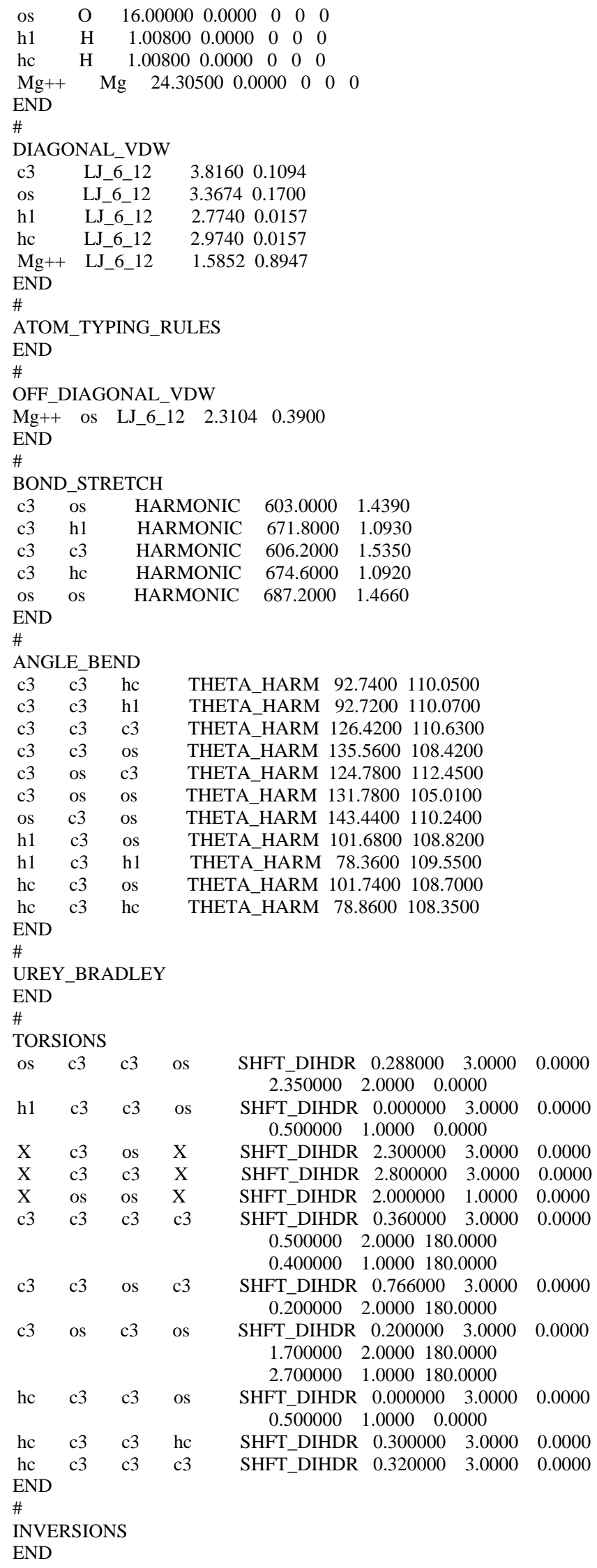


\#

COULOMBIC

$\begin{array}{lll}X & X & \text { CONST-EPS }\end{array}$

TFSI-anion

VERSION

CERIUS2 1

END

\#

HEADER

END

\#

PREFERENCES

BONDS

ANGLES

COULOMB

INVERSIONS

TORSIONS

UREY_BRADLEY

STRETCH_STRETCH

$\mathrm{T}$

$\mathrm{T}$

$\mathrm{T}$

$\mathrm{T}$

$\mathrm{T}$

SEPARATED STRETCH STRETCH

STRETCH_BEND_STRETCH

BEND_BEND

TORSION_STRETCH

TORSION_BEND_BEND

BEND_TORSION_BEND

STRETCH_TORSION_STRETCH

HYDROGEN_BONDS

DIAGONAL VAN DER WAALS

OFF_DIAGONAL_VAN_DER_WAALS

GENERATE_UNDEFINED_TERMS

IGNORE_UNDEFINED_TERMS

NON-BONDED_3-BODY

SHRINK_CH_BONDS

SHRINK_CH_H_ATOM

SHRINK_CH_FACTOR

SINGLE_TORSION

F

F

F

SCALE_TORSIONS_ABOUT_COMMON_BOND F

SCALE_BY_N_DEFINED_TORSIONS T T

EXOCYCLIC_TORSIONS_SCALE_FACTOR 1.00000

SINGLE_INVERSION T

H-BOND_METHOD

H-BOND_LIST

TPLINE

H-BOND_DIRECT_RCUT 4.00000

H-BOND_SPLINE_DISTANCE_ON $\quad 4.00000$

H-BOND SPLINE_DISTANCE_OFF 4.50000

H-BOND_SPLINE_ANGLE_ON $\quad 65.00000$

H-BOND SPLINE ANGLE OFF $\quad 75.00000$

H-BOND_LIST_DISTANCE_OFF 6.50000

H-BOND_LIST_ANGLE_OFF

NON_BOND_LIST

NON BOND BUFFER_DISTANCE

H-BOND_BUFFER_DISTANCE

COU_DIELETRIC_CONSTANT

COU_INTER_CUT_OFF

COU_SPLINE_OFF

COU_SPLINE_ON

EWALD_SUM_COU_ACCURACY

EWALD_SUM_COU_ETA

EWALD_SUM_COU_KCUT

EWALD_SUM_COU_RCUT

EWALD_SUM_COU_AUTO_OPT

COU EXCLUDE 1-2

COU_EXCLUDE_1-3

COU_EXCLUDE_1-4

COU_1-4_SCALE_FACTOR

COU METHOD

COU_DIRECT_CUT-OFF

90.00000

$T$

$$
2.00000
$$

2.00000

1.00000000000000000

50.00000

10.00000

9.00000

0.00100

2.50000

0.50000

6.00000

$\mathrm{T}$

$\mathrm{T}$

$\mathrm{T}$

$\mathrm{F}$

0.83000

EWALD

8.00000 


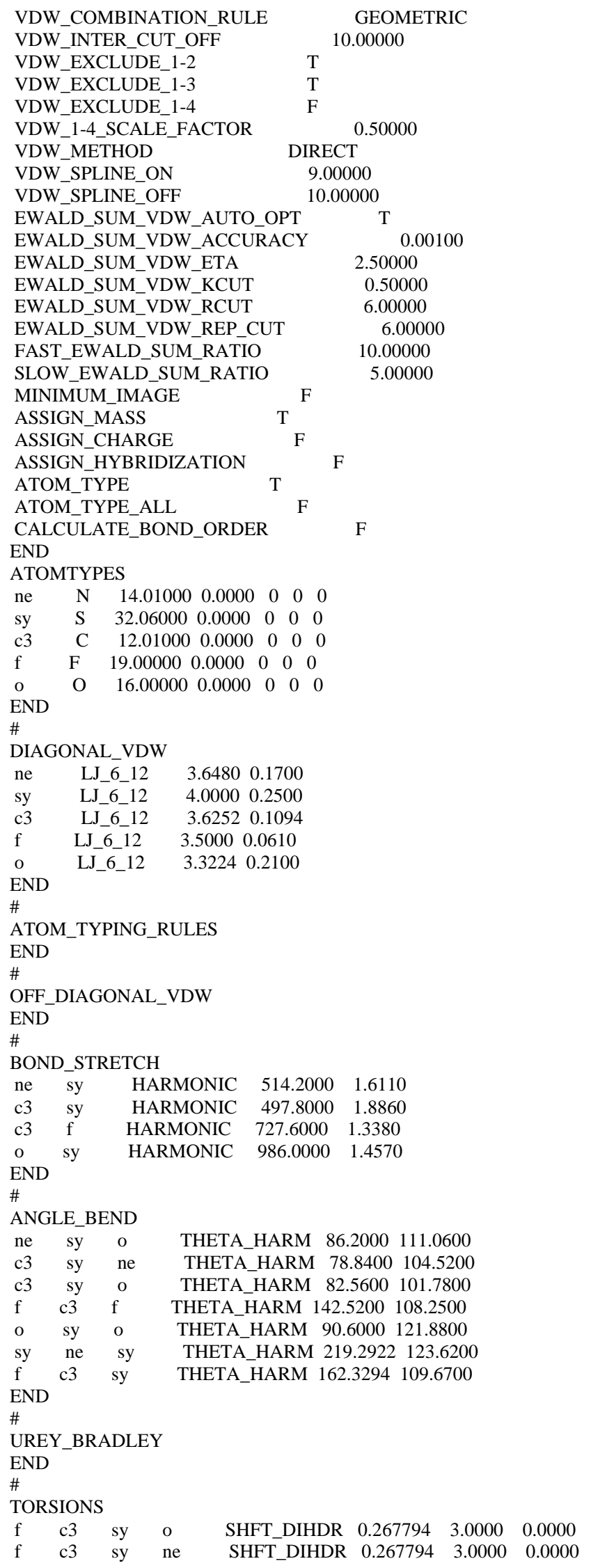




$\begin{array}{lllllllll}\text { sy } & \text { ne } & \text { sy } & \text { o } & & \text { SHFT_DIHDR } & 0.519332 & 3.0000 & 180.0000 \\ \text { sy } & \text { ne } & \text { sy } & \text { c3 } & & \text { SHFT_DIHDR } & 0.519332 & 3.0000 & 180.0000\end{array}$

\section{Equilibrium structures of MgTFSI+/6THF complexes Level of theory: B3LYP5-D3/6-311++G** PCM (COSMO) $\varepsilon($ THF $)=7.58$}

\section{$\mathrm{MgTFSI}^{+} / 6 \mathrm{THF}$ bidentate structure}

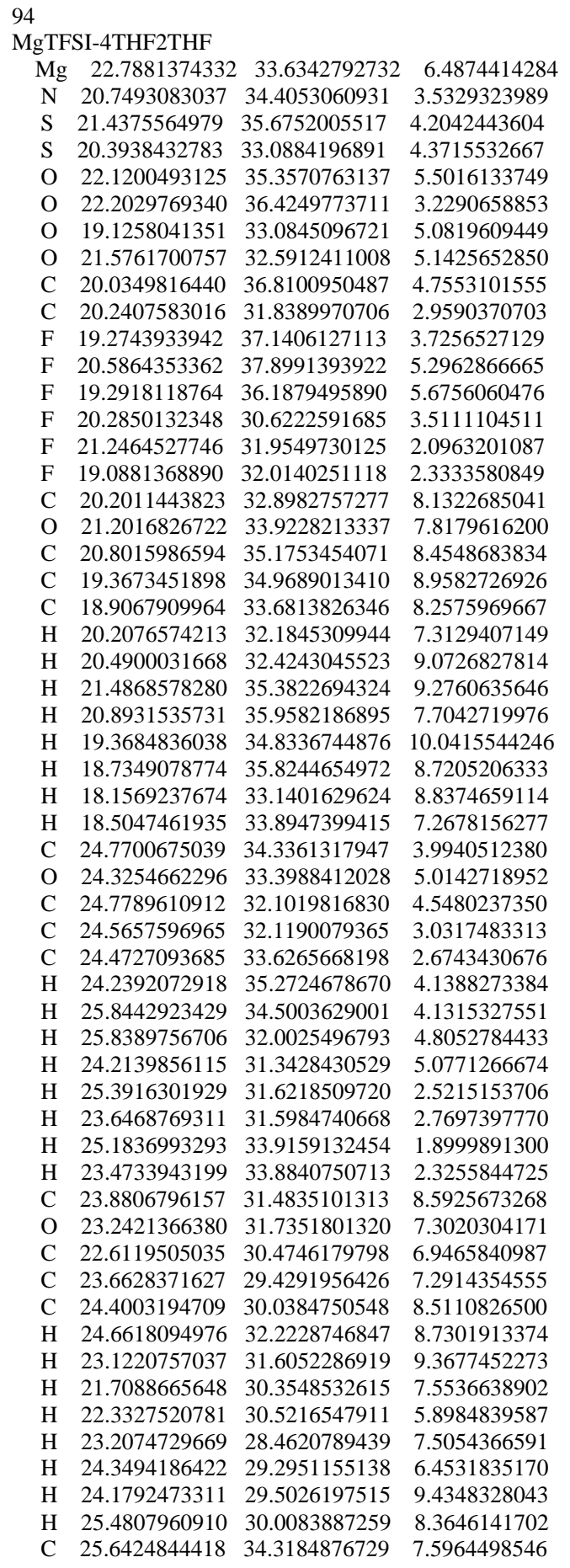




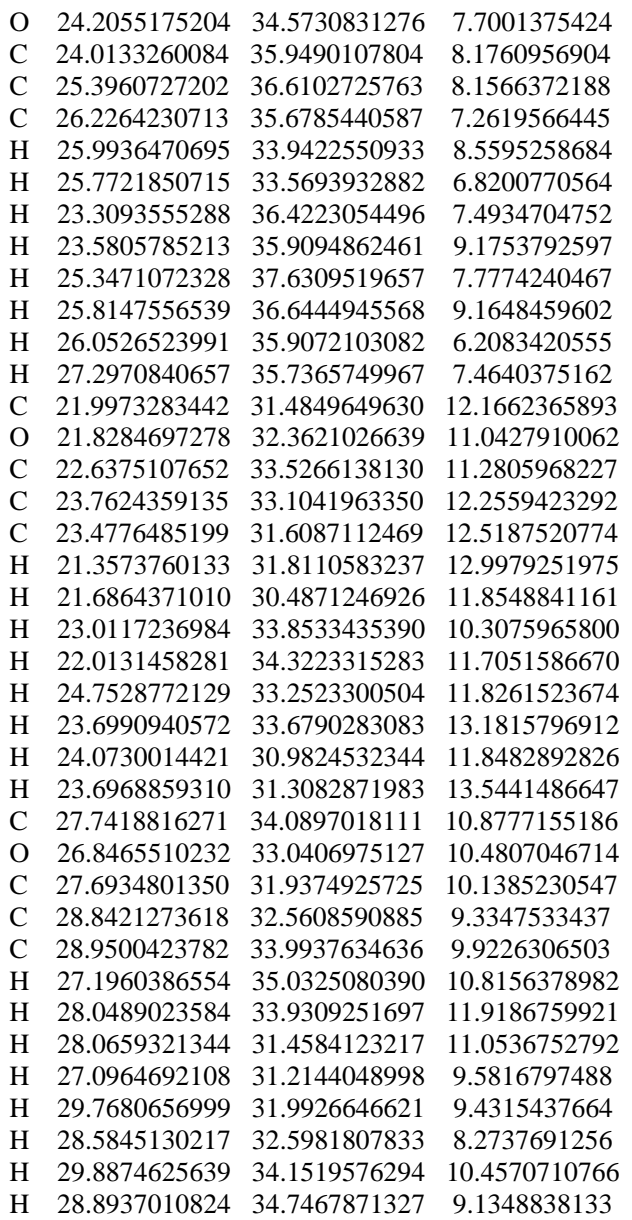

$\mathrm{MgTFSI}^{+} / 6 \mathrm{THF}$ monodentate structure

$\begin{array}{cccc}94 \\ \text { MgTFSI-5THFTHF } & & \\ \text { Mg } & 31.5977725658 & 36.0761504593 & 25.4164862536 \\ \text { N } & 34.7374684021 & 37.6213391215 & 25.8224277226 \\ \text { S } & 36.1241748612 & 38.1799403627 & 26.4960248251 \\ \text { S } & 34.0232263274 & 38.0942779937 & 24.5014155412 \\ \text { O } & 36.1681897139 & 37.5501754937 & 27.8088476085 \\ \text { O } & 37.2546984926 & 38.1176193251 & 25.5869994118 \\ \text { O } & 33.5884927686 & 39.4838154810 & 24.4232331245 \\ \text { O } & 32.9519878630 & 37.0715292494 & 24.2671476292 \\ \text { C } & 35.8409820207 & 40.0262344017 & 26.8308965650 \\ \text { C } & 35.1223218930 & 37.8041842303 & 22.9855805052 \\ \text { F } & 34.5946413219 & 40.2332702971 & 27.2846482410 \\ \text { F } & 36.0180754620 & 40.7202449171 & 25.7108775953 \\ \text { F } & 36.7118521092 & 40.4327334447 & 27.7521508885 \\ \text { F } & 34.3358620761 & 37.6451148589 & 21.9113948061 \\ \text { F } & 35.8385945880 & 36.6900429079 & 23.1622584267 \\ \text { F } & 35.9190260755 & 38.8419302019 & 22.8033778935 \\ \text { C } & 28.7240873381 & 37.1882418206 & 24.6500864217 \\ \text { O } & 30.1319693356 & 37.4838937674 & 24.8080003242 \\ \text { C } & 30.3183888418 & 38.7854522163 & 24.1801445872 \\ \text { C } & 29.0802992431 & 39.5917723083 & 24.5844956557 \\ \text { C } & 28.0111586045 & 38.5158286426 & 24.9211228174 \\ \text { H } & 28.5570952145 & 36.8424461127 & 23.6249548168 \\ \text { H } & 28.4778083794 & 36.3870895838 & 25.3399979393 \\ \text { H } & 31.2650186430 & 39.1914813769 & 24.5190768097 \\ \text { H } & 30.3648601948 & 38.6358527402 & 23.0970572405\end{array}$


$\begin{array}{llll}\text { H } & 29.2921577122 & 40.2127264954 & 25.4552800946\end{array}$

$\begin{array}{llll}\mathrm{H} & 28.7650656781 & 40.2522807751 & 23.7769383881\end{array}$

$\begin{array}{lllll}\mathrm{H} & 27.7090584744 & 38.5840667447 & 25.9674192059\end{array}$

$\begin{array}{lllll}\mathrm{H} & 27.1131291031 & 38.6137558162 & 24.3103997142\end{array}$

$\begin{array}{llll}\text { C } & 31.4224789813 & 33.0286170491 & 30.6478551850\end{array}$

$\begin{array}{llll}\text { O } & 31.3953036590 & 34.3986759998 & 30.1824697792\end{array}$

$\begin{array}{llll}\text { C } \quad 31.0830588678 & 35.2606358348 & 31.2916229215\end{array}$

C $\quad 30.1985737790 \quad 34.4146682072 \quad 32.1980277855$

$\begin{array}{llll}\text { C } & 30.8743994861 & 33.0377485889 & 32.0871471507\end{array}$

H $\quad 30.8008835446 \quad 32.4395629086 \quad 29.9666284067$

$\begin{array}{lllll}\mathrm{H} & 32.4482591277 & 32.6525908304 & 30.5965833949\end{array}$

H $\quad 32.0061727191 \quad 35.5637497135 \quad 31.8020928940$

$\begin{array}{lllll}\mathrm{H} & 30.5978891370 & 36.1531014843 & 30.8898944195\end{array}$

H $\quad 30.1568141590 \quad 34.7873791936 \quad 33.2222133509$

$\begin{array}{lllll}\mathrm{H} & 29.1793480357 & 34.3824629908 & 31.8019513703\end{array}$

H $\quad 31.6933287834 \quad 32.9619798800 \quad 32.8060007699$

H $30.1895432128 \quad 32.2100797339 \quad 32.2745462864$

C $\quad 31.6462482025 \quad 33.6632773764 \quad 23.2832888315$

$\begin{array}{llll}\text { O } & 31.1930128813 & 35.0005703558 & 23.6114291620\end{array}$

C $\quad 31.0406271174 \quad 35.7375926452 \quad 22.3531510656$

$\begin{array}{llll}\text { C } & 31.8185549900 & 34.9467052261 & 21.2865717259\end{array}$

$\begin{array}{llll}\text { C } & 32.5618526400 & 33.8629554780 & 22.0890607067\end{array}$

$\begin{array}{llll}\mathrm{H} & 32.1311738081 & 33.2546702878 & 24.1646784571\end{array}$

H $\quad 30.7748844251 \quad 33.0490433087 \quad 23.0291246557$

H $\quad 29.9747530435 \quad 35.8050875171 \quad 22.1272711207$

H $\quad 31.4497656629 \quad 36.7271793606 \quad 22.5280727252$

H $\quad 31.1315516815 \quad 34.4907564768 \quad 20.5710687336$

H $\quad 32.5036804383 \quad 35.5879225297 \quad 20.7328762641$

H $\quad 32.7148217943 \quad 32.9455354065 \quad 21.5198556486$

$\begin{array}{lllll}\mathrm{H} & 33.5354193301 & 34.2274173022 & 22.4230921632\end{array}$

C $\quad 32.8595239786 \quad 36.7576516797 \quad 28.2359661494$

$\begin{array}{lllll}\text { O } & 31.9425728835 & 37.1948719535 & 27.1682328002\end{array}$

$\begin{array}{llll}\text { C } & 31.5700121512 & 38.5846606493 & 27.3903964351\end{array}$

$\begin{array}{llll}\text { C } & 31.8043381883 & 38.8256398593 & 28.8735118175\end{array}$

$\begin{array}{llll}\text { C } & 33.0313478434 & 37.9523843843 & 29.1685221987\end{array}$

$\begin{array}{lllll}\text { H } & 32.3895747784 & 35.9104060427 & 28.7301648901\end{array}$

H $\quad 33.7914462456 \quad 36.4646177646 \quad 27.7670837459$

$\begin{array}{lllll}\mathrm{H} & 32.2023673589 & 39.2249944524 & 26.7709614800\end{array}$

H $\quad 30.530909966938 .6974277606 \quad 27.0858713299$

H $\quad 31.9760555664 \quad 39.8801999853 \quad 29.0902225896$

$\begin{array}{llll}\mathrm{H} & 30.9384437350 & 38.4953352649 & 29.4550955331\end{array}$

H $\quad 33.9531116787 \quad 38.4835748620 \quad 28.9390132531$

$\begin{array}{lllll}\mathrm{H} & 33.0813075740 & 37.6370018746 & 30.2113981961\end{array}$

C $\quad 32.8299513744 \quad 33.6137125606 \quad 27.1229656019$

$\begin{array}{lllll}\text { O } & 32.9545534741 & 34.5641351866 & 26.0269722457\end{array}$

C $\quad 34.2976219493 \quad 34.3755828079 \quad 25.4929729063$

$\begin{array}{llll}\text { C } & 35.1739732477 & 34.1740311405 & 26.7228153524\end{array}$

C $\quad 34.2249283668 \quad 33.5138760869 \quad 27.7551911728$

$\begin{array}{lllll}\mathrm{H} & 32.0670408324 & 33.9860340819 & 27.7975314703\end{array}$

H $\quad 32.5100639338 \quad 32.6531872859 \quad 26.7042186725$

$\begin{array}{lllll}\mathrm{H} & 34.2875368455 & 33.4906371324 & 24.8466371354\end{array}$

H $\quad 34.5450275166 \quad 35.2546611084 \quad 24.9114969765$

H $\quad 36.0427434434 \quad 33.5548476598 \quad 26.4972505509$

H $\quad 35.5325192009 \quad 35.1355545297 \quad 27.0876974041$

H $\quad 34.4855165814 \quad 32.4714052553 \quad 27.9424990739$

H $\quad 34.2567125085 \quad 34.0410996822 \quad 28.7085617731$

$\begin{array}{llll}\text { C } & 29.4824233848 & 35.4635234412 & 27.7046975980\end{array}$

$\begin{array}{lllll}\text { O } & 30.1331118710 & 35.0084879759 & 26.4690956275\end{array}$

C $\quad 29.5322662495 \quad 33.7571330440 \quad 26.0209072169$

$\begin{array}{llll}\text { C } & 28.6527057591 & 33.2963758237 & 27.1763092622\end{array}$

C $\quad 28.2167979944 \quad 34.6240934482 \quad 27.8100302093$

$\begin{array}{lllll}\mathrm{H} & 30.1627046494 & 35.2641085131 & 28.5317831750\end{array}$

H $\quad 29.3081815258 \quad 36.5334066382 \quad 27.6068188619$

$\begin{array}{lllll}\mathrm{H} & 28.9594546090 & 33.9637199421 & 25.1133394511\end{array}$

H $\quad 30.3380164898 \quad 33.0660223563 \quad 25.7802792472$

H $\quad 27.8172295766 \quad 32.6843995563 \quad 26.8351599835$

H $\quad 29.2368564791 \quad 32.7093561983 \quad 27.8900156837$

$\begin{array}{lllll}\mathrm{H} & 27.3983034470 & 35.0726192715 & 27.2400914524\end{array}$

H $\quad 27.8892669096 \quad 34.5142825687 \quad 28.8445043107$ 


\section{$\mathrm{MgTFSI}^{+} / 6 \mathrm{THF}$ solvent separated ion-pair structure}

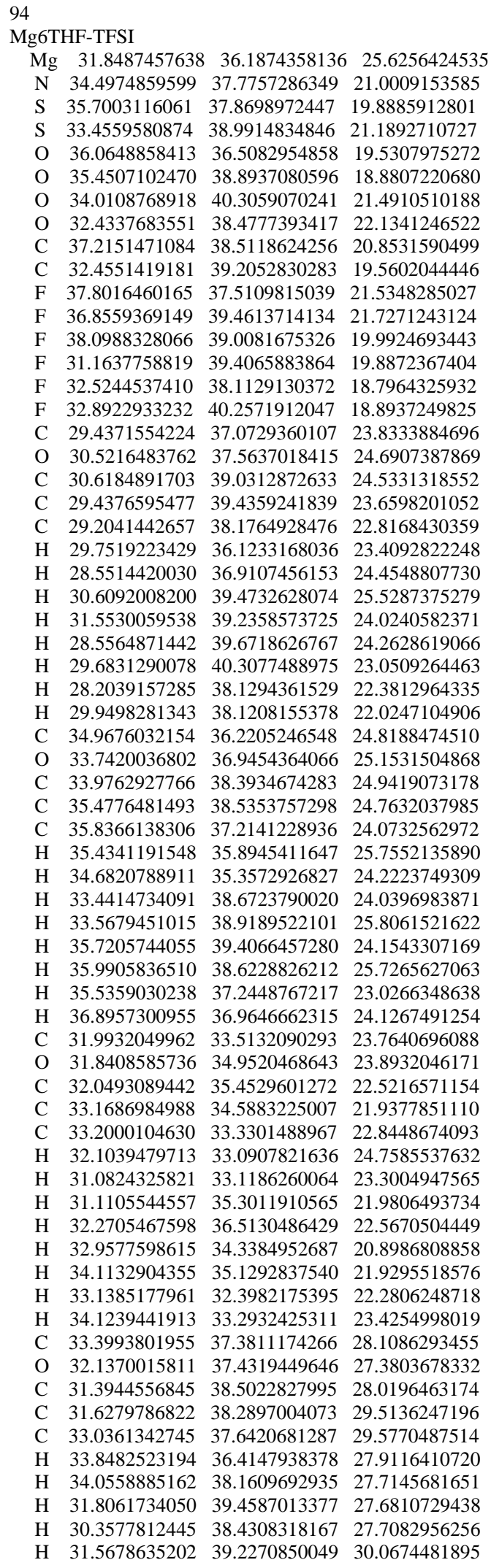




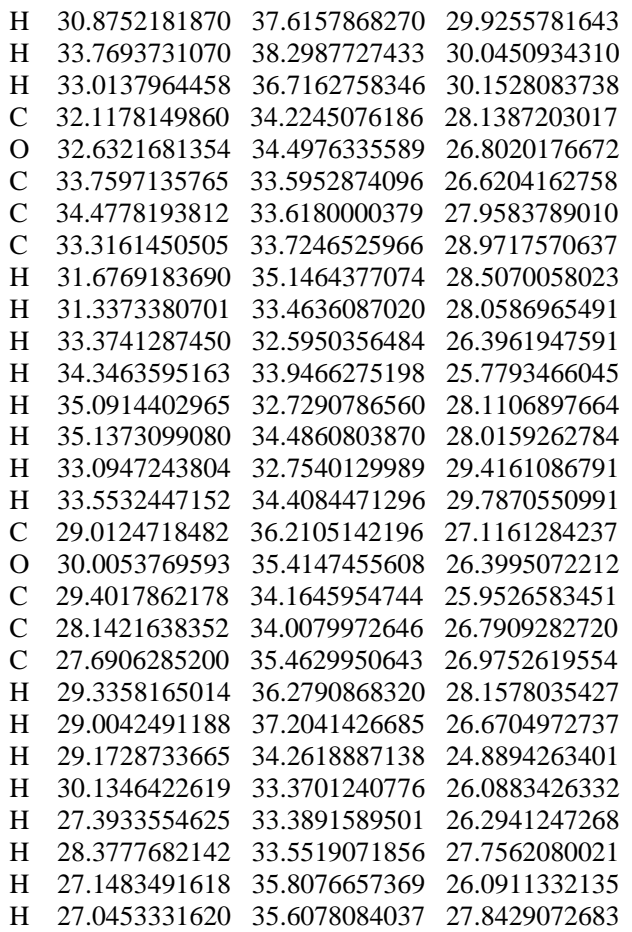

\section{References}

[1] J. Wang, R. M. Wolf, J. W. Caldwell, P. A. Kollman, D. A. Case, J. Comput. Chem. 2004, 25, 1157.

[2] J. Aqvist, J. Phys. Chem. 1990, 94, 8021-8024.

[3] S. Plimpton, J. Comp. Phys. 1995, 117, 1.

[4] S. A. Nosé, J. Chem. Phys. 1984, 81, 511.

[5] W. G. Hoover, Phys. Rev. A: At. Mol. Opt. Phys. 1985, 31, 1965.

[6] G. J. Martyna, M. L. Klein, M. Tuckerman, J. Chem. Phys. 1992, 97 (4), 2635-2643.

[7] J. Hutter, M. Iannuzzi, F. Schiffmann, J. VandeVondele, Wiley Interdiscip. Rev. Comput. Mol. Sci. 2014, 4, 15-25.

[8] J. VandeVondele, J. Hutter, J. Chem. Phys., 2007, 127, 114105.

[9] S. Goedecker, M. Teter, J. Hutter, Phys. Rev. B 1996, 54(3), 1703-1710.

[10] S. Grimme, J. Antony, S. Ehrlich, H. Krieg, J. Chem. Phys. 2010, 132(15), 154104.

[11] I. S. Ufimtsev, T. J. Martinez, J. Chem. Theory Comput. 2009, 5, 2619.

[12] S. Zahn, D. R. MacFarlane, E. I. Izgorodina, Phys. Chem. Chem. Phys. 2013, 15, 13664.

[13] S. Grimme, J. Antony, S. Ehrlich, H. Krieg, J. Chem. Phys. 2010, 132, 154104.

[14] J. Kästner, J. M. Carr, T. W. Keal, W. Thiel, A. Wander, P. Sherwood, J. Phys. Chem. A 2009, 113, 11856.

[15] A. Klamt, G. J. Schüürmann, Chem. Soc., Perkin Trans. 2 1993, 799-805.

[16] A. J. Bondi, Phys. Chem. 1964, 68, 441-451.

[17] V. S. Bryantsev, M. S. Diallo, and W. A. Goddard III, J. Phys. Chem. 2008, 112, 9709.

[18] J. Kästner, Wiley Inter. Rev.: Comp. Mol. Sci. 2011, 1, 932-942. 
[19] A. L. Ferguson, J. Compt. Chem. 2017, 38, 1583-1605.

[20] A. Laio, F. L. Gervasio, Rep. Prog. Phys. 2008, 71, 126601.

[21] A. Barducci, M. Bonomi, M. Parrinello, Wiley Inter. Rev.: Comp. Mol. Sci. 2011, 1, 826-843.

[22] A. Baskin and D. Prendergast, J. Phys. Chem. Lett., 2019, 10, 4920-4928.

[23] D. Trzesniak, A.-P. E. Kunz, W.F. van Gunsteren, ChemPhysChem, 2007, 8, 162-169. 